\title{
Impact of the South Asian monsoon outflow on atmospheric hydroperoxides in the upper troposphere
}

\author{
Bettina Hottmann $^{1}$, Sascha Hafermann ${ }^{1}$, Laura Tomsche ${ }^{1,4}$, Daniel Marno ${ }^{1}$, Monica Martinez ${ }^{1}$, Hartwig Harder ${ }^{1}$, \\ Andrea Pozzer ${ }^{1}$, Marco Neumaier ${ }^{2}$, Andreas Zahn $^{2}$, Birger Bohn $^{3}$, Greta Stratmann $^{4}$, Helmut Ziereis $^{4}$, \\ Jos Lelieveld $^{1}$, and Horst Fischer ${ }^{1}$ \\ ${ }^{1}$ Atmospheric Chemistry Department, Max Planck Institute for Chemistry, 55128 Mainz, Germany \\ ${ }^{2}$ Karlsruhe Institute of Technology, 76021 Karlsruhe, Germany \\ ${ }^{3}$ Forschungszentrum Jülich GmbH, 52425 Jülich, Germany \\ ${ }^{4}$ German Aerospace Center, Institute of Atmospheric Physics, 82234 Oberpfaffenhofen, Germany
}

Correspondence: Bettina Hottmann (bettina.hottmann@mpic.de) and Horst Fischer (horst.fischer@mpic.de)

Received: 31 January 2020 - Discussion started: 19 February 2020

Revised: 17 August 2020 - Accepted: 20 August 2020 - Published: 3 November 2020

\begin{abstract}
During the OMO (Oxidation Mechanism Observation) mission, trace gas measurements were performed on board the HALO (High Altitude Long Range) research aircraft in summer 2015 in order to investigate the outflow of the South Asian summer monsoon and its influence on the composition of the Asian monsoon anticyclone (AMA) in the upper troposphere over the eastern Mediterranean and the Arabian Peninsula. This study focuses on in situ observations of hydrogen peroxide $\left(\mathrm{H}_{2} \mathrm{O}_{2}{ }^{\text {obs }}\right)$ and organic hydroperoxides $\left(\mathrm{ROOH}^{\mathrm{obs}}\right)$ as well as their precursors and loss processes. Observations are compared to photostationary-state (PSS) calculations of $\mathrm{H}_{2} \mathrm{O}_{2}{ }^{\text {PSS }}$ and extended by a separation of $\mathrm{ROOH}^{\mathrm{obs}}$ into methyl hydroperoxide (MHP ${ }^{\mathrm{PSS}}$ ) and inferred unidentified hydroperoxide (UHP ${ }^{\text {PSS }}$ ) mixing ratios using PSS calculations. Measurements are also contrasted to simulations with the general circulation ECHAM-MESSy for Atmospheric Chemistry (EMAC) model. We observed enhanced mixing ratios of $\mathrm{H}_{2} \mathrm{O}_{2}{ }^{\text {obs }}(45 \%)$, MHPPS $(9 \%)$, and $\mathrm{UHP}^{\mathrm{PSS}}(136 \%)$ in the AMA relative to the northern hemispheric background. Highest concentrations for $\mathrm{H}_{2} \mathrm{O}_{2}{ }^{\text {obs }}$ and MHP ${ }^{\mathrm{PSS}}$ of 211 and $152 \mathrm{ppb}_{\mathrm{v}}$, respectively, were found in the tropics outside the AMA, while for UHPPSS, with $208 \mathrm{ppt}_{\mathrm{v}}$, highest concentrations were found within the AMA. In general, the observed concentrations are higher than steady-state calculations and EMAC simulations by a factor of 3 and 2, respectively. Especially in the AMA, EMAC underestimates the $\mathrm{H}_{2} \mathrm{O}_{2}{ }^{\text {EMAC }}$ (medians: 71 ppt $_{\mathrm{v}}$ vs. 164 ppt $_{\mathrm{v}}$ ) and $\mathrm{ROOH}^{\mathrm{EMAC}}$ (medians: $25 \mathrm{ppt}_{\mathrm{v}}$ vs. $278 \mathrm{ppt}_{\mathrm{v}}$ ) mixing ratios.
\end{abstract}

Longitudinal gradients indicate a pool of hydroperoxides towards the center of the AMA, most likely associated with upwind convection over India. This indicates main contributions of atmospheric transport to the local budgets of hydroperoxides along the flight track, explaining strong deviations from steady-state calculations which only account for local photochemistry. Underestimation of $\mathrm{H}_{2} \mathrm{O}_{2}$ EMAC by approximately a factor of 2 in the Northern Hemisphere $(\mathrm{NH})$ and the AMA and overestimation in the Southern Hemisphere (SH; factor 1.3) are most likely due to uncertainties in the scavenging efficiencies for individual hydroperoxides in deep convective transport to the upper troposphere, corroborated by a sensitivity study. It seems that the observed excess $\mathrm{UHP}^{\mathrm{PSS}}$ is excess MHP transported to the west from an upper tropospheric source related to convection in the summer monsoon over Southeast Asia.

\section{Introduction}

The earth has an oxidizing atmosphere where $\mathrm{OH}$ functions as the main oxidizing agent (Levy, 1971). OH is formed by the photolysis of ozone $(\lambda<320 \mathrm{~nm})$ and subsequent reaction of the produced singlet $\mathrm{D}$ oxygen atom $\left(\mathrm{O}^{1} \mathrm{D}\right)$ with water vapor. The main sinks of $\mathrm{OH}$ are also the main sources of peroxy radicals $\left(\mathrm{HO}_{2}\right.$ and $\left.\mathrm{RO}_{2}\right)$ in the reactions with $\mathrm{CO}$, $\mathrm{CH}_{4}$, and volatile organic compounds (VOCs) and the reaction with nitrogen dioxide $\left(\mathrm{NO}_{2}\right)$ to form nitric acid $\left(\mathrm{HNO}_{3}\right)$. 
At low $\mathrm{NO}_{x}\left(\mathrm{NO}+\mathrm{NO}_{2}\right)$ concentrations, $\mathrm{HO}_{2}$ reacts with itself to form $\mathrm{H}_{2} \mathrm{O}_{2}$ or with $\mathrm{RO}_{2}$ to form organic hydroperoxides (ROOH). Since $\mathrm{HO}_{2}, \mathrm{RO}_{2}$, and especially $\mathrm{CH}_{3} \mathrm{O}_{2}$ react faster with $\mathrm{NO}$ than with $\mathrm{HO}_{2}$, peroxides are mainly produced in areas with low $\mathrm{NO}$ and high $\mathrm{OH}$ mixing ratios (Lee et al., 2000). $\mathrm{H}_{2} \mathrm{O}_{2}$ is a strong oxidant in the aqueous phase, oxidizing for example $\mathrm{SO}_{2}$ to $\mathrm{H}_{2} \mathrm{SO}_{4}$, and hence $\mathrm{H}_{2} \mathrm{O}_{2}$ partially contributes to acid rain formation (e.g., Hoffmann and Edwards, 1975; Penkett et al., 1979; Robbin Martin and Damschen, 1981; Calvert et al., 1985). The major photochemical sinks of hydroperoxides are photolysis, which recycles $\mathrm{OH}$, and the reaction with $\mathrm{OH}$ forms $\mathrm{HO}_{2}$. Physical loss of hydroperoxides due to dry and wet deposition establishes an ultimate loss mechanism of $\mathrm{HO}_{x}$ radicals. Thus $\mathrm{H}_{2} \mathrm{O}_{2}$ and $\mathrm{ROOH}$ play a pivotal role in the $\mathrm{HO}_{x}$ budget and modulate the oxidation capacity of the atmosphere (Lelieveld and Crutzen, 1990; Crutzen et al., 1999).

The global distribution of hydroperoxides is affected by transport, physical removal by dry deposition and rainout, and net photochemical production processes. With increasing altitude - and thus decreasing water vapor concentration - the primary production of $\mathrm{HO}_{x}$ decreases (Heikes et al., 1996) and leads to an increasing contribution of the photolysis of $\mathrm{H}_{2} \mathrm{O}_{2}$ and $\mathrm{ROOH}$ to the $\mathrm{HO}_{x}$ budget (Jaeglé et al., 1997, 2000; Faloona et al., 2000, 2004). In more polluted areas, especially in the boundary layer, the $\mathrm{H}_{2} \mathrm{O}_{2}$ chemistry is more complex and leads to higher variabilities (Nunnermacker et al., 2008). Close to the surface, dry deposition of $\mathrm{H}_{2} \mathrm{O}_{2}$ forms a strong sink, resulting in decreasing concentrations with decreasing altitude. This often leads to a local maximum of $\mathrm{H}_{2} \mathrm{O}_{2}$ mixing ratios above the boundary layer at 2-5 km of altitude (Daum et al., 1990; Heikes, 1992; Weinstein-Lloyd et al., 1998; Snow, 2003; Snow et al., 2007; Klippel et al., 2011). A similar but weaker maximum at 2$5 \mathrm{~km}$ was found for methyl hydroperoxide (MHP; WeinsteinLloyd et al., 1998; Snow, 2003; Snow et al., 2007). Due to its lower deposition velocity associated with less efficient uptake by solid and aqueous surfaces, MHP is not as sensitive to deposition processes as $\mathrm{H}_{2} \mathrm{O}_{2}$ (Lind and Kok, 1986, 1994), yielding rather constant mixing ratios with altitude within the boundary layer. Further, the mixing ratios of both species generally decrease with increasing latitude in the free troposphere due to lower water vapor concentrations (Jacob and Klockow, 1992; Perros, 1993; Slemr and Tremmel, 1994; Snow, 2003; Snow et al., 2007; Klippel et al., 2011).

In spite of several in situ measurement campaigns of trace gases in the outflow of the Asian summer monsoon in the recent years, e.g., from the IAGOS-CARIBIC (In-Service Aircraft for a Global Observing System - Civil Aircraft for the Regular Investigation of the atmosphere Based on an Instrument Container) project (Ojha et al., 2016; RautheSchöch et al., 2016), the IAGOS-MOZAIC (Measurement of Ozone and Water Vapour on Airbus in-service Aircraft) project (Barret et al., 2016), the MINOS (Mediterranean Intensive Oxidant Study) aircraft campaign (Lelieveld et al.,
2002), and the PEM-WEST (Pacific Exploratory MissionWest) A mission (Heikes et al., 1996), our understanding of the physical and chemical processes within the Asian monsoon anticyclone (AMA) is limited. So far we know that the updrafts of the summer monsoon deep convection can effectively transport insoluble pollutants from the surface to the upper troposphere, and there these polluted air masses can be transported over a long distance (Lawrence and Lelieveld, 2010). Thus the Asian summer monsoon has a strong influence on the upper troposphere (UT) and the lower stratosphere (Randel et al., 2010; Gettelman et al., 2004), and it is important to study its physical and chemical properties in greater detail.

The focus of the OMO (Oxidation Mechanism Observation) campaign was to investigate photochemical processes in the AMA in the UT. During the mission, the HALO (High Altitude and Long Range) research aircraft probed a large variety of air masses, ranging from clean Northern Hemisphere $(\mathrm{NH})$ background air above the western Mediterranean to Southern Hemisphere $(\mathrm{SH})$ background air over the northern Indian Ocean and air masses affected by the South Asian summer monsoon in the AMA over the Arabian Peninsula. The main goals of the campaign were to analyze the influence of the AMA on the oxidizing power of the atmosphere and to determine the rates at which natural and human-made compounds are converted by oxidation processes in the atmosphere (Lelieveld et al., 2018).

The present study addresses the budgets of $\mathrm{H}_{2} \mathrm{O}_{2}$ and organic hydroperoxides. Since the measurements of the sum of all organic hydroperoxides do not differentiate between different species, we estimate the contribution from MHP ${ }^{\mathrm{PSS}}$ based on steady-state calculations. In former studies MHP was identified as the most abundant organic hydroperoxide in the free troposphere (Heikes et al., 1996; Jackson and Hewitt, 1996). Our goal was to investigate the extent to which this is also the case for the outflow of the South Asian summer monsoon into the UT. In addition the in situ data were compared to results from the ECHAM-MESSy for Atmospheric Chemistry (EMAC) model (see Sect. 4.3.2) along the flight track for $\mathrm{H}_{2} \mathrm{O}_{2}$ and individual $\mathrm{ROOH}$ mixing ratios. $\mathrm{H}_{2} \mathrm{O}_{2}{ }^{\text {obs }}$ mixing ratios were also evaluated with steady-state calculations based on measured $\mathrm{HO}_{x}$ and photolysis frequency measurements on board HALO.

\section{The OMO project}

The OMO campaign took place from 21 July to $27 \mathrm{Au}-$ gust 2015. During the campaign 17 flights with the HALO research aircraft were performed. The airports of Oberpfaffenhofen (Germany), Paphos (Cyprus), Gan (Maldives), and Bahrain served as bases for takeoffs and landings. The flights were mainly performed over the Arabian Peninsula, the eastern Mediterranean, and the northern Indian Ocean $\left(0.2^{\circ} \mathrm{S}-\right.$ $\left.48.1^{\circ} \mathrm{N}, 11.3-80.2^{\circ} \mathrm{E}\right)$. In Fig. 1 the tracks of all $\mathrm{OMO}$ 
flights are shown. The aircraft reached altitudes up to $15 \mathrm{~km}$, which corresponds to $130 \mathrm{hPa}$, to study the chemistry of the UT.

\section{Methods}

\subsection{Hydroperoxide measurements}

The hydroperoxide data $\left(\mathrm{H}_{2} \mathrm{O}_{2}{ }^{\text {obs }}\right.$ and total organic hydroperoxides, $\mathrm{ROOH}^{\mathrm{obs}}$ ) during OMO were obtained using a modified commercial instrument (AEROLASER, model AL2021, Garmisch-Partenkirchen, Germany) called HYPHOP (hydrogen peroxide and higher organic peroxide monitor). The HYPHOP instrument was installed in a $19^{\prime \prime}$ rack together with the infrared laser absorption instrument TRISTAR (tracer in situ TDLAS for atmospheric research) mounted in the back of HALO. Air was sampled from the top of the aircraft fuselage through a forward-facing trace gas inlet (TGI) designed as a bypass, consisting of a $1 / 2^{\prime \prime}$ PFA (perfluoroalkoxy alkane) tube inside the aircraft with an exit through a second TGI. From this bypass, air was sampled at a flow rate of $2 \mathrm{slpm}$ (standard liters per minute) through a $1 / 4^{\prime \prime}$ PFA tube and directed to HYPHOP. To obtain constant pressure at the HYPHOP inlet, a constant pressure inlet (CPI) consisting of a dual-stage membrane pump (Vacuubrand MD1C VARIO SP, Wertheim, Germany) was used (Klippel et al., 2011).

HYPHOP relies on a dual-enzyme detection method after transfer of gaseous hydroperoxides into a buffered solution (potassium hydrogen phthalate and $\mathrm{NaOH}, \mathrm{pH} 6$ ) in a glass stripping coil (Lazrus et al., 1985, 1986). This stripper also contains EDTA (ethylenediaminetetraacetic acid) to prevent the reaction of transition metal ions with the hydroperoxides. Additionally, formaldehyde ( $\mathrm{HCHO}$ ) is added to prevent the oxidation of dissolved $\mathrm{SO}_{2}$ (in alkaline solutions $\mathrm{HSO}_{3}^{-}$) by the hydroperoxides. Instead, $\mathrm{HCHO}$ and $\mathrm{HSO}_{3}^{-}$form hydroxymethyl sulfonate $\left(\mathrm{HOCH}_{2} \mathrm{SO}_{3}^{-}\right)$. After the stripping coil the hydroperoxide-containing solution is divided into two channels. Catalase is added to one channel in order to selectively destroy $\mathrm{H}_{2} \mathrm{O}_{2}$. This first channel thus measures only $\mathrm{ROOH}$, while the second channel (without catalase) measures the sum of $\mathrm{ROOH}$ and $\mathrm{H}_{2} \mathrm{O}_{2}$. Since hydroperoxides cannot be detected by fluorescence directly, a second enzyme (horseradish peroxidase) and $p$-hydroxyphenylacetic acid (POPHA) are added to both channels. In a quantitative and selective reaction, the enzyme catalyzes the oxidation of POPHA by hydroperoxides, forming the fluorescent dye 6,6'-dihydroxy-3,3'-biphenyldiacetid acid. After excitation at $326 \mathrm{~nm}$ with a Cd lamp, the fluorescence at 400$420 \mathrm{~nm}$ is detected. To enlarge the fluorescence intensity, sodium hydroxide is added.

In order to perform zero measurements, the sampled air is directed through a cylinder filled with Hopcalite $\left(\mathrm{MnO}_{2}\right.$ and $\mathrm{CuO}$ ) to eliminate $\mathrm{H}_{2} \mathrm{O}_{2}, \mathrm{ROOH}$, and ozone. Since the efficiency of Hopcalite decreases with increased humidity, the air is dried beforehand with the help of orange gel $\left(\mathrm{SiO}_{2}\right.$ beads plus indicator).

To convert the detected signal into a concentration, a fourpoint calibration was performed before and after every flight. In the first two steps a liquid standard of $\mathrm{H}_{2} \mathrm{O}_{2}(1 \mu \mathrm{mol} \mathrm{L}-1$; freshly diluted from stock solution) followed by zero air is measured in both channels without catalase. Afterwards this is repeated with catalase in the $\mathrm{ROOH}$ channel for the last two steps. The sensitivity for both channels and the catalase efficiency are determined via this procedure. The concentration of the liquid standard is based on titration of the stock solution $\left(10 \mathrm{mmol} \mathrm{L}^{-1}\right)$ with potassium permanganate.

To determine the stripping efficiency for $\mathrm{H}_{2} \mathrm{O}_{2}$, a gasphase standard based on a permeation source (Teflon tube filled with $30 \% \mathrm{H}_{2} \mathrm{O}_{2}$ in a temperature-controlled glass flask) is used at a constant flow rate of approximately $40 \mathrm{sccm}$, diluted with synthetic air and measured with the instrument. The permeation rate of the source is quantified by collecting the output of the source into cooled water. The addition of hydrochloric titanium tetrachloride yields the formation of the yellow $\eta^{2}$-peroxo complex $\left[\mathrm{Ti}\left(\eta^{2}-\mathrm{O}_{2}\right) \mathrm{Cl}_{4}\right]^{2-}$ (Pilz and Johann, 1974), whose concentration is determined via a UV photometer. The stripping efficiency of MHP was assumed to be $60 \%$ and that of $\mathrm{H}_{2} \mathrm{O}_{2}$ to be $100 \%$ (AEROLASER, 2006; Lee et al., 2000).

The inlet efficiency was determined with the help of the permeation source, which was measured with and without the CPI. In laboratory studies the inlet efficiency was determined to be $87 \% \pm 3 \%$, decreasing during the campaign to $62.7 \% \pm 0.8 \%$, which is mainly due to the higher humidity.

The limit of detection (LOD) and precisions for $\mathrm{H}_{2} \mathrm{O}_{2}$ and MHP (assuming total $\mathrm{ROOH}^{\mathrm{obs}}$ to be only MHP), respectively, have been calculated for each flight from the reproducibility ( $1 \sigma$ standard deviation) of in-flight zero (650 values) and liquid calibration (100 values) measurements, taking into account the sensitivity, stripping, and catalase efficiency. LOD values are in the range of $8-53 \mathrm{ppt}_{\mathrm{v}}$ for $\mathrm{H}_{2} \mathrm{O}_{2}{ }^{\text {obs }}$ (median $23 \mathrm{ppt}_{\mathrm{v}}$ ) and 9-52 $\mathrm{ppt}_{\mathrm{v}}$ for $\mathrm{ROOH}^{\mathrm{obs}}$ (median $23 \mathrm{ppt}_{\mathrm{v}}$ ), respectively, assuming that $\mathrm{ROOH}^{\mathrm{obs}}$ is composed of MHP only. Please note that due to the fact that the exact composition of $\mathrm{ROOH}^{\mathrm{obs}}$ is unknown, and the solubility of different $\mathrm{ROOH}$ species can be quite variable, a detection limit for $\mathrm{ROOH}^{\mathrm{obs}}$ cannot be given. Instead, we calculate an upper limit of the detection limit, assuming that all $\mathrm{ROOH}^{\mathrm{obs}}$ consists of MHP, the species with the smallest solubility. Precision values were determined from the reproducibility of standard measurements and are in the range of $0.2 \%$ at $5.2 \mathrm{ppb}_{\mathrm{v}}$ and $1.3 \%$ at $5.9 \mathrm{ppb}_{\mathrm{v}}$ for $\mathrm{H}_{2} \mathrm{O}_{2}$ and $0.3 \%$ at $5.0 \mathrm{ppb}_{\mathrm{v}}$ and $2.1 \%$ at $6.0 \mathrm{ppb}_{\mathrm{v}}$ for MHP. The time resolution (signal increase from $10 \%$ to $90 \%$ ) of the instrument is $120 \mathrm{~s}$. An ozone interference of $53 \mathrm{ppt}_{\mathrm{v}} \mathrm{H}_{2} \mathrm{O}_{2}$ per $100 \mathrm{ppb}_{\mathrm{v}}$ $\mathrm{O}_{3}$, which was determined by $\mathrm{H}_{2} \mathrm{O}_{2}$ measurements in the stratosphere during the OMO-EU test campaign, was taken into account and corrected. 


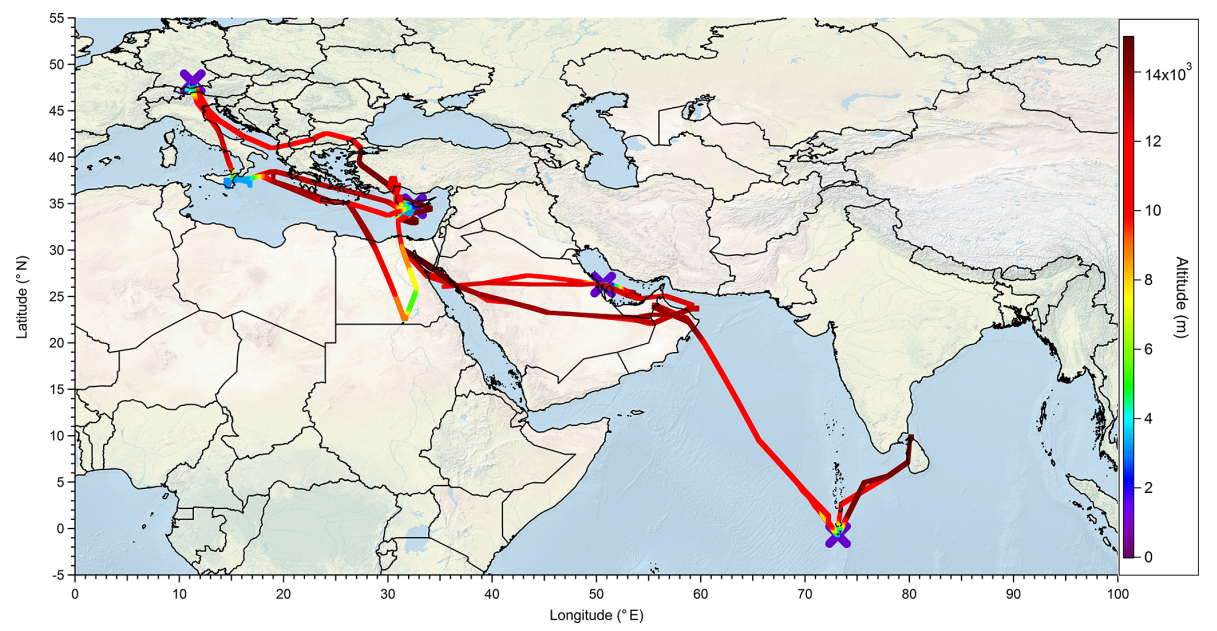

Figure 1. Flight tracks (colors indicate altitude) and airports (purple crosses) used during the OMO campaign.

The total uncertainty calculated from statistical errors and uncertainties of liquid standard, inlet and stripping efficiency, and ozone interference is $25 \%$ for $\mathrm{H}_{2} \mathrm{O}_{2}$ and $40 \%$ for MHP.

\subsection{Other in situ measurements}

For this study $\mathrm{CO}, \mathrm{CH}_{4}, \mathrm{OH}, \mathrm{HO}_{2}, \mathrm{O}_{3}$, acetone, $\mathrm{NO}, \mathrm{NO}_{y}$, $J_{\mathrm{H}_{2} \mathrm{O}_{2}}$, and $J_{\mathrm{MHP}}$ data measured by other instruments have been used for data interpretation, steady-state calculations, and interference corrections (see Sect. 3.1). A complete list of all measured compounds can be found in Lelieveld et al. (2018). $\mathrm{CO}$ and $\mathrm{CH}_{4}$ have been measured by the IR quantum cascade laser absorption spectrometer TRISTAR (Schiller et al., 2008; Tadic et al., 2017). The measurements comprised an ambient-air mode and in-flight calibrations. The latter were realized with secondary standards from pressurized bottles (6L bottle, Auer GmbH, Germany), which were calibrated against certified reference gases (Tomsche et al., 2019). With the help of the in-flight calibrations, the in situ data are drift-corrected by interpolation between two calibrations (Tadic et al., 2017). The observed $\mathrm{CO}$ and $\mathrm{CH}_{4}$ mixing ratios have a total uncertainty of $5.1 \%$ and $0.275 \%$, respectively. The relatively high $\mathrm{CO}$ uncertainty reflects problems with the stability of the $\mathrm{CO}$ quantum cascade laser during the second half of OMO.

Laser-induced fluorescence was the method utilized for $\mathrm{HO}_{x}$ measurements (instrument name: HORUS; Faloona et al., 2004; Martinez et al., 2010). The accuracies of the measurements are $17.1 \%$ for $\mathrm{OH}$ and $17.6 \%$ for $\mathrm{HO}_{2}$. The limit of detection of the instrument does vary depending on altitude as this system has a sensitivity that depends on pressure. As altitude increases the LOD decreases from $0.1 \mathrm{ppt}_{\mathrm{v}}$ to $0.02 \mathrm{ppt}_{\mathrm{v}}$ for $\mathrm{OH}$ and 0.361 to $0.175 \mathrm{ppt}_{\mathrm{v}}$ for $\mathrm{HO}_{2}$.

FAIRO (fast airborne ozone instrument) is a lightweight $(14.5 \mathrm{~kg})$ and accurate two-sensor device for measuring $\mathrm{O}_{3}$. It combines two techniques, i.e., (a) a UV photometer that measures the light absorption by $\mathrm{O}_{3}$ at a wavelength of $\lambda=250-260 \mathrm{~nm}$ emitted by a UV-LED and (b) a chemiluminescence detector that monitors the chemiluminescence generated by $\mathrm{O}_{3}$ on the surface of an organic dye adsorbed on dry silica gel. These techniques are simultaneously applied in order to combine the high measurement accuracy of the UV photometry with the high measurement frequency of the chemiluminescence detection. The UV photometer has a $1 \sigma$ precision of $0.08 \mathrm{ppb}_{\mathrm{v}}$ at a measurement frequency of $0.25 \mathrm{~Hz}$ (and a pressure of $1 \mathrm{bar}$ ) and an accuracy of $1.5 \%$ (determined by the uncertainty of the $\mathrm{O}_{3}$ cross section). The chemiluminescence detector has a precision of $0.05 \mathrm{ppb}_{\mathrm{v}}$ at a measurement frequency of $12.5 \mathrm{~Hz}$ (Zahn et al., 2012). In postprocessing the chemiluminescence detector data are calibrated using the UV photometer data.

Nitrogen oxide (NO) and total reactive nitrogen $\left(\mathrm{NO}_{y}\right)$ were measured using the AENEAS atmospheric nitrogen oxide measuring system. The measurements were performed by a dual-channel NO chemiluminescence detector (CLD-SR 790, Eco Physics, Switzerland) in combination with a converter technique for the detection of total reactive nitrogen as NO. $\mathrm{NO}_{y}$ comprises, among others, $\mathrm{NO}, \mathrm{NO}_{2}, \mathrm{HNO}_{3}, \mathrm{NO}_{3}$, $\mathrm{N}_{2} \mathrm{O}_{5}, \mathrm{HNO}_{2}, \mathrm{HO}_{2} \mathrm{NO}_{2}$, PAN, and organic nitrates. The individual $\mathrm{NO}_{y}$ species were detected after conversion to $\mathrm{NO}$ using a gold tube maintained at about $300^{\circ} \mathrm{C}$, with $\mathrm{H}_{2}$ as a reducing agent (Ziereis et al., 2000). Ambient air was sampled using a standard HALO trace gas inlet equipped with a heated $\left(\sim 40^{\circ} \mathrm{C}\right)$ PFA inlet line. The time resolution of the measurements was about $1 \mathrm{~s}$. The overall uncertainty of the $\mathrm{NO}$ and $\mathrm{NO}_{y}$ measurements depends on its ambient concentrations and is about $8 \%(6.5 \%)$ for volume mixing ratios of $0.5 \mathrm{nmol} \mathrm{mol}^{-1}\left(1 \mathrm{nmol} \mathrm{mol}^{-1}\right)$, respectively (Stratmann et al., 2016).

VOCs (e.g., acetone) were measured with a homebuilt lightweight $(\sim 55 \mathrm{~kg}$ without rack) proton-transfer-reaction mass spectrometer, which uses a commercial quadrupole 
mass analyzer (Pfeiffer, QMA 410, Germany). A modular V25 microcomputer system (MPI-C, Mainz, Germany) is applied for instrument control and data acquisition. A custombuilt inlet system comprises a platinum-quartz wool scrubber (Shimadzu, High Sensitivity Catalyst) held at $300^{\circ} \mathrm{C}$ and components for flow and pressure control. The instrument was calibrated between flights with a dynamically diluted gas standard containing approximately $500 \mathrm{ppb}_{\mathrm{v}}$ of VOCs (ApelRiemer Environmental Inc., USA). The accuracy for acetone is typically $\pm 10 \%$, and the detection limit is $\sim 60 \mathrm{ppt}_{\mathrm{v}}$.

Photolysis frequencies were calculated from spectral actinic flux density spectra $(280-650 \mathrm{~nm})$ obtained from charge-coupled device (CCD) spectroradiometer measurements on the top and bottom fuselage of the aircraft, covering the upper and the lower hemisphere, respectively (Bohn and Lohse, 2017). Recent recommendations of absorption cross sections and quantum yields were used in the calculations as well as their temperature and pressure dependencies (if available) by taking into account measured static air temperatures and pressures. Radiometric uncertainties range around $5 \%-$ $6 \%$ under typical flight conditions. Additional uncertainties related to the molecular parameters are process-specific. For $\mathrm{H}_{2} \mathrm{O}_{2}$ in particular, recommended absorption cross sections and their temperature dependencies were applied, and unity quantum yields were assumed (Burkholder et al., 2015). However, the recommended $\mathrm{H}_{2} \mathrm{O}_{2}$ absorption cross sections are confined to a wavelength range below $350 \mathrm{~nm}$, which is insufficient to capture atmospheric photolysis completely. Because measured cross sections decay exponentially over 2 orders of magnitude in the range of $280-350 \mathrm{~nm}$, this dependence was further extrapolated up to $370 \mathrm{~nm}$, where values drop well below $10^{-22} \mathrm{~cm}^{2}$. Dependent on conditions, this extrapolation increases atmospheric $\mathrm{H}_{2} \mathrm{O}_{2}$ photolysis frequencies by $10 \%-20 \%$. For MHP the temperature dependence of the absorption cross sections is unknown. Therefore the recommended room temperature data were used under all conditions as well as unity quantum yields (Burkholder et al., 2015). Combined total uncertainties of $15 \%$ and $25 \%$ are estimated for $\mathrm{H}_{2} \mathrm{O}_{2}$ and MHP photolysis frequencies, respectively.

Latitude, longitude, and altitude data as well as temperature and pressure were collected with the BAHAMAS (basic HALO measurement and sensor system) instrument. More detailed information about the installation of scientific instruments and mission flights can be found at http: //www.halo.dlr.de/science/missions/omo/omo.html (last access: 27 February 2019).

\subsection{Photostationary-state calculations}

Since only the sum of organic hydroperoxides was measured, we estimated the contribution of MHP using a photostationary-state (PSS) approximation relying on in situ measurements of $\mathrm{HO}_{2}, \mathrm{OH}, \mathrm{CO}, \mathrm{CH}_{4}, \mathrm{NO}, J_{\mathrm{MHP}}$, and $J_{\mathrm{H}_{2} \mathrm{O}_{2}}$ (see Sect. 3.2) and rate coefficient data from Atkinson et al. $(2004,2006)$.

In the free troposphere the production rate $P$ of $\mathrm{H}_{2} \mathrm{O}_{2}$ and MHP is due to the self-reaction of $\mathrm{HO}_{2}$ and reaction of $\mathrm{CH}_{3} \mathrm{O}_{2}$ with $\mathrm{HO}_{2}$, respectively, and can be calculated from Eqs. (1) and (2).

$$
\begin{aligned}
& P\left(\mathrm{H}_{2} \mathrm{O}_{2}\right)=k_{\mathrm{HO}_{2}+\mathrm{HO}_{2}} \cdot\left[\mathrm{HO}_{2}\right]^{2} \\
& P(\mathrm{MHP})=k_{\mathrm{CH}_{3} \mathrm{O}_{2}+\mathrm{HO}_{2}} \cdot\left[\mathrm{CH}_{3} \mathrm{O}_{2}\right] \cdot\left[\mathrm{HO}_{2}\right]
\end{aligned}
$$

Photochemical loss rates $L$ of $\mathrm{H}_{2} \mathrm{O}_{2}$ and MHP are due to photolysis and reaction with $\mathrm{OH}$ according to Eqs. (3) and (4).

$$
\begin{aligned}
& L\left(\mathrm{H}_{2} \mathrm{O}_{2}\right)=\left(k_{\mathrm{H}_{2} \mathrm{O}_{2}+\mathrm{OH}} \cdot[\mathrm{OH}]+J_{\mathrm{H}_{2} \mathrm{O}_{2}}\right) \cdot\left[\mathrm{H}_{2} \mathrm{O}_{2}\right] \\
& L(\mathrm{MHP})=\left(k_{\mathrm{MHP}+\mathrm{OH}} \cdot[\mathrm{OH}]+J_{\mathrm{MHP}}\right) \cdot[\mathrm{MHP}]
\end{aligned}
$$

For steady-state conditions the production and loss reactions are at equilibrium, and the MHP ${ }^{\mathrm{PSS}}$-to- $\mathrm{H}_{2} \mathrm{O}_{2}{ }^{\text {obs }}$ ratio can be calculated from Eq. (5).

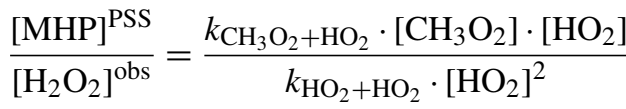

$$
\begin{aligned}
& \cdot \frac{k_{\mathrm{H}_{2} \mathrm{O}_{2}}+\mathrm{OH} \cdot[\mathrm{OH}]+J_{\mathrm{H}_{2} \mathrm{O}_{2}}}{k_{\mathrm{MHP}+\mathrm{OH}} \cdot[\mathrm{OH}]+J_{\mathrm{MHP}}}
\end{aligned}
$$

Because individual peroxy radicals were not measured, the $\mathrm{CH}_{3} \mathrm{O}_{2}$-to- $\mathrm{HO}_{2}$ ratio must be estimated from their production and loss terms. This ratio can be deduced as written in Eq. (6).

$$
\frac{\left[\mathrm{CH}_{3} \mathrm{O}_{2}\right]}{\left[\mathrm{HO}_{2}\right]}=\frac{L\left(\mathrm{HO}_{2}\right) \cdot P\left(\mathrm{CH}_{3} \mathrm{O}_{2}\right)}{P\left(\mathrm{HO}_{2}\right) \cdot L\left(\mathrm{CH}_{3} \mathrm{O}_{2}\right)}
$$

Dominant loss processes for $\mathrm{HO}_{2}$ and $\mathrm{CH}_{3} \mathrm{O}_{2}$ are reactions with $\mathrm{NO}$ and the production of $\mathrm{H}_{2} \mathrm{O}_{2}$ and MHP, respectively, neglecting the production of peroxy nitrates due to low $\mathrm{NO}_{2}$ concentrations in the UT (Eqs. 7 and 8).

$$
\begin{gathered}
L\left(\mathrm{HO}_{2}\right)=k_{\mathrm{CH}_{3} \mathrm{O}_{2}+\mathrm{HO}_{2}} \cdot\left[\mathrm{CH}_{3} \mathrm{O}_{2}\right] \cdot\left[\mathrm{HO}_{2}\right]+k_{\mathrm{HO}_{2}+\mathrm{NO}} \\
\cdot\left[\mathrm{HO}_{2}\right] \cdot[\mathrm{NO}]+k_{\mathrm{HO}_{2}+\mathrm{HO}_{2}} \cdot\left[\mathrm{HO}_{2}\right]^{2} \\
\begin{aligned}
L\left(\mathrm{CH}_{3} \mathrm{O}_{2}\right) & =k_{\mathrm{CH}_{3} \mathrm{O}_{2}+\mathrm{HO}_{2}} \cdot\left[\mathrm{CH}_{3} \mathrm{O}_{2}\right] \cdot\left[\mathrm{HO}_{2}\right] \\
& +k_{\mathrm{CH}_{3} \mathrm{O}_{2}+\mathrm{NO}} \cdot\left[\mathrm{CH}_{3} \mathrm{O}_{2}\right] \cdot[\mathrm{NO}]
\end{aligned}
\end{gathered}
$$

The first terms on the right side of both equations are identical. The second terms are dominated by the rate coefficients of the reactions with NO and the NO concentration. For the calculations of the rate coefficients, the mean temperature of $259.18 \mathrm{~K}$, the mean altitude of $10992.8 \mathrm{~m}$, and the mean pressure of $22932.9 \mathrm{~Pa}$ were used. The resulting values are shown in Eqs. (9)-(11). As the relative humidity is very low in the upper troposphere, the water dependence in Eq. (11) was neglected.

$$
\begin{aligned}
k_{\mathrm{HO}_{2}+\mathrm{NO}} & =3.45 \times 10^{-12} \cdot \exp ^{\frac{270}{T}} \\
& =9.78 \times 10^{-12} \mathrm{~cm}^{3}(\text { molec. } \mathrm{s})^{-1}
\end{aligned}
$$




$$
\begin{aligned}
k_{\mathrm{CH}_{3} \mathrm{O}_{2}+\mathrm{NO}} & =2.3 \times 10^{-12} \cdot \exp ^{\frac{360}{T}} \\
& =9.22 \times 10^{-12} \mathrm{~cm}^{3}(\text { molec. s) })^{-1} \\
k_{\mathrm{HO}_{2}+\mathrm{HO}_{2}}= & 2.2 \times 10^{-13} \cdot \exp ^{\frac{600}{T}} \\
+ & 1.9 \times 10^{-33} \cdot\left[\mathrm{N}_{2}\right] \cdot \exp ^{\frac{980}{T}} \\
& =2.64 \times 10^{-12} \mathrm{~cm}^{3}(\text { molec. s })^{-1}
\end{aligned}
$$

This indicates that the reaction of $\mathrm{HO}_{2}$ with $\mathrm{NO}$ is more than a factor of 3 faster than the self-reaction. The measured NO concentration is an order of magnitude larger than measured $\mathrm{HO}_{2}$ so that reaction with $\mathrm{NO}$ is the dominant process for both $\mathrm{HO}_{2}$ and $\mathrm{CH}_{3} \mathrm{O}_{2}$, resulting in similar loss rates for both radicals in the UT. Thus, the ratio of $\mathrm{CH}_{3} \mathrm{O}_{2}$ to $\mathrm{HO}_{2}$ is dominated by their production rates (Eq. 12).

$$
\frac{\left[\mathrm{CH}_{3} \mathrm{O}_{2}\right]}{\left[\mathrm{HO}_{2}\right]}=\frac{P\left(\mathrm{CH}_{3} \mathrm{O}_{2}\right)}{P\left(\mathrm{HO}_{2}\right)}=\frac{k_{\mathrm{CH}_{4}+\mathrm{OH}} \cdot\left[\mathrm{CH}_{4}\right] \cdot[\mathrm{OH}]}{k_{\mathrm{CO}+\mathrm{OH}} \cdot[\mathrm{CO}] \cdot[\mathrm{OH}]}
$$

The combination of Eqs. (5) and (12) results in Eq. (13), which was used to calculate the MHP ${ }^{\mathrm{PSS}}$ concentrations based on the observed mixing ratios during OMO.

$$
\begin{aligned}
{[\mathrm{MHP}]^{\mathrm{PSS}}=} & \frac{k_{\mathrm{CH}_{3} \mathrm{O}_{2}+\mathrm{HO}_{2}}}{k_{\mathrm{HO}_{2}+\mathrm{HO}_{2}}} \\
& \cdot \frac{k_{\mathrm{H}_{2} \mathrm{O}_{2}+\mathrm{OH}} \cdot[\mathrm{OH}]^{\mathrm{obs}}+J_{\mathrm{H}_{2} \mathrm{O}_{2}}^{\mathrm{obs}}}{k_{\mathrm{MHP}+\mathrm{OH}} \cdot[\mathrm{OH}]^{\mathrm{obs}}} \\
& +J_{\mathrm{MHP}}^{\mathrm{obs}} \cdot \frac{k_{\mathrm{CH}}+\mathrm{OH} \cdot\left[\mathrm{CH}_{4}\right]^{\mathrm{obs}}}{k_{\mathrm{CO}+\mathrm{OH}} \cdot[\mathrm{CO}]^{\mathrm{obs}}} \cdot\left[\mathrm{H}_{2} \mathrm{O}_{2}\right]^{\mathrm{obs}}
\end{aligned}
$$

Please note that other sources of $\mathrm{HO}_{2}$ and $\mathrm{CH}_{3} \mathrm{O}_{2}$, in particular the photolysis of formaldehyde ( $\mathrm{HCHO}$ ) and acetaldehyde, respectively have been neglected. This is justified by the generally low mixing ratios of these species at high altitudes. Measurements of HCHO with the TRISTAR instrument yielded values below the detection limit of $30 \mathrm{ppt}_{\mathrm{v}}$ (parts per trillion by volume), and although acetaldehyde was not measured, we assume that its mixing ratio is within a factor of 2 of those for HCHO.

The total uncertainty of MHP ${ }^{\mathrm{PSS}}$ from the calculation according to Eq. (13) can be deduced from error propagation, taking into account uncertainties in $\mathrm{OH}^{\mathrm{obs}}(17.1 \%)$, $J_{\mathrm{H}_{2} \mathrm{O}_{2}}^{\text {obs }}(15 \%), J_{\mathrm{MHP}}^{\text {obs }}(25 \%), \mathrm{CH}_{4}^{\text {obs }}(0.275 \%), \mathrm{CO}^{\text {obs }}(5.1 \%)$, $\mathrm{H}_{2} \mathrm{O}_{2}$ obs $(25 \%)$, and rate constants, to be of the order of $45 \%$ $(1 \sigma)$.

To estimate the contribution of MHP to the total organic hydroperoxides, the calculated concentration of MHP ${ }^{\mathrm{PSS}}$ was subtracted from the measured sum of all organic hydroperoxides $\mathrm{ROOH}^{\mathrm{obs}}$. This leads to a concentration of unidentified organic hydroperoxides (UHP ${ }^{\mathrm{PSS}}$; Eq. 14). Please note that $\mathrm{MHP}^{\mathrm{PSS}}$ only accounts for local $\mathrm{CH}_{4}$ oxidation production and not for transport phenomena.

$[\mathrm{UHP}]^{\mathrm{PSS}}=[\mathrm{ROOH}]^{\mathrm{obs}}-[\mathrm{MHP}]^{\mathrm{PSS}}$

\section{$3.4 \quad \mathrm{H}_{2} \mathrm{O}_{2}$ calculation}

In order to classify the measured $\mathrm{H}_{2} \mathrm{O}_{2}{ }^{\text {obs }}, \mathrm{HO}_{2}{ }^{\text {obs }}$, and $\mathrm{OH}^{\text {obs }}$ data, we calculated $\mathrm{H}_{2} \mathrm{O}_{2}{ }^{\mathrm{PSS}}$ from measured $\mathrm{HO}_{x}$ and $J_{\mathrm{H}_{2} \mathrm{O}_{2}}^{\text {obs }}$. For the calculation, Eq. (15) was used, which is based on Eqs. (1) and (3).

$$
\left[\mathrm{H}_{2} \mathrm{O}_{2}\right]^{\mathrm{PSS}}=\frac{\left[\mathrm{HO}_{2}\right]^{\mathrm{obs} 2} \cdot k_{\mathrm{HO}_{2}+\mathrm{HO}_{2}}}{[\mathrm{OH}]^{\mathrm{obs}} \cdot k_{\mathrm{H}_{2} \mathrm{O}_{2}+\mathrm{OH}}+J_{\mathrm{H}_{2} \mathrm{O}_{2}}^{\mathrm{oss}}}
$$

A total uncertainty of $45 \%(1 \sigma)$ due to uncertainties in $\mathrm{OH}^{\mathrm{obs}}(17.1 \%), \mathrm{HO}_{2}{ }^{\mathrm{obs}}(17.6 \%), J_{\mathrm{H}_{2} \mathrm{O}_{2}}^{\mathrm{obs}}(15 \%)$, and reaction rate constants was calculated.

\subsection{Other research tools}

The EMAC (ECHAM-MESSy atmospheric chemistry) model comprises the fifth generation of the European Center Hamburg (ECHAM5; Roeckner et al., 2006; version 5.3.01) general circulation model and the Modular Earth Submodel System (MESSy; Jöckel et al., 2016; version 2.52, http: //www.messy-interface.org/, last access: 25 August 2019). For this study EMAC simulations (T42L90, $2.8^{\circ} \times 2.8^{\circ}$ horizontal resolution, 90 vertical levels to $0.01 \mathrm{hPa}$, time resolution $12 \mathrm{~min}$ ) were sampled along the OMO flights tracks. Detailed specifications and results have been published previously (Lelieveld et al., 2018; Tomsche et al., 2019).

Back trajectories of $10 \mathrm{~d}$ were calculated along the flight path using FLEXPART to identify the air mass origin (Tomsche et al., 2019). Convective transport can be simulated in FLEXPART with the convection parameterization by Emanuel and Zivkovic-Rothman (1999). To represent moist convection realistically in models, the parametrization includes cloud microphysical processes, the physics of entrainment and mixing, and large-scale control of ensemble convective activity. It builds on temperature and humidity fields to provide mass flux information (Stohl et al., 2005). The back trajectories in the present paper are calculated with the convective parametrization. Further, the Lagrangian particle dispersion model FLEXPART produces so-called centroid trajectories based on the analysis of a cluster of trajectories. These trajectories are comparable to traditional trajectories but include convection via the centroid of all particles per time step. As indicated by Tomsche et al. (2019), prominent source regions of AMA air masses are identified to be the Indo-Gangetic Plain, northeastern India, Bangladesh, and the Bay of Bengal. Additionally, Tomsche et al. used observations of methane to differentiate between air masses influenced by the AMA and background air. A comparison of vertical profiles indicated that the air inside the AMA showed significantly higher $\mathrm{CH}_{4}$ concentrations than outside. Thus a threshold of $\mathrm{CH}_{4} \geq 1879.8 \mathrm{ppb}_{\mathrm{v}}$ was used to distinguish between air masses influenced by the AMA $\left(\mathrm{CH}_{4} \geq\right.$ $\left.1879.8 \mathrm{ppb}_{\mathrm{v}}\right)$, the $\mathrm{SH}$ background $\left(\mathrm{CH}_{4}<1820 \mathrm{ppb}_{\mathrm{v}}\right)$, and the NH background $\left(1820 \mathrm{ppb}_{\mathrm{v}} \leq \mathrm{CH}_{4}<1879.8 \mathrm{ppb}_{\mathrm{v}}\right.$; Tomsche et al., 2019). 


\section{Results and discussion}

\subsection{Data processing}

Data were collected from a merged data set given as $60 \mathrm{~s}$ means (calculated from the original data set obtained at higher resolutions) in order to get the same time resolution for all compounds. The given time is the middle of the block mean.

For the histograms the concentrations of all species shown were binned into samples with a width of $10 \mathrm{ppt}_{\mathrm{v}}$, starting with the plots with the lowest bin. To compare the simulations from EMAC with measured and PSS-calculated data, the corresponding values (out of the $60 \mathrm{~s}$ means) were used at the given times from EMAC.

\subsection{Case study: Flight 17 from Gan to Bahrain (10 August 2015)}

In a case study analyzing Flight 17 from 10 August 2015, the method used to determine the origin of the measured air masses and a quantification and comparison of measured and simulated mixing ratios of $\mathrm{H}_{2} \mathrm{O}_{2}{ }^{\text {obs }}, \mathrm{MHP}^{\mathrm{PSS}}$, and $\mathrm{UHP}^{\mathrm{PSS}}$ is presented. During this flight we encountered the $\mathrm{SH}$ and $\mathrm{NH}$ as well as the AMA in the UT. The flight track is shown in Fig. 2 (dotted line). Takeoff was in Gan (Maldives) and landing in Bahrain, on the Arabian Peninsula. Besides takeoff and landing, the entire flight took place in the UT $(<230 \mathrm{hPa})$. The calculated back trajectories show the origin of the air masses. At the beginning of the flight the measured air masses had their origin over the Indian Ocean and Indonesia. During the remaining flight the measured air stemmed from India. Tomsche et al. (2019) showed that the measured air in the AMA was affected by deep convection over India, resulting in methane mixing ratios above the threshold. Figure 3 shows the time series for $\mathrm{H}_{2} \mathrm{O}_{2}{ }^{\text {obs }}$ during the flight at the time steps given from the frequency of EMAC output (orange circles). The colored bar on top shows the origin of air masses, i.e., red for AMA, green for $\mathrm{NH}$, and blue for $\mathrm{SH}$. The $\mathrm{H}_{2} \mathrm{O}_{2}{ }^{\text {obs }}$ mixing ratios vary between 128 and 366 ppt $_{\mathrm{v}}$. The modeled $\mathrm{H}_{2} \mathrm{O}_{2}{ }^{\text {EMAC }}$ data are in the range of 110-799 $\mathrm{ppt}_{\mathrm{v}}$ (gray triangles). For the beginning of the flight, model simulations agree rather well with the measurement data. At around 06:00 UTC the model-calculated mixing ratios increase to more than $500 \mathrm{ppt}_{\mathrm{v}}$, while the measured data decrease to $200 \mathrm{ppt}_{\mathrm{v}}$ and lower. In this period a maximum difference between model and in situ data of $386 \mathrm{ppt}_{\mathrm{v}}$ was found. After $1 \mathrm{~h}$ the EMAC model data decrease to $416 \mathrm{ppt}_{\mathrm{v}}$, and the in situ data increase to $214 \mathrm{ppt}_{\mathrm{v}}$. During the following hour until around 08:00 UTC and thus at higher altitude, both mixing ratios increase, with the modeled data showing a much stronger increase up to approximately $800 \mathrm{ppt}_{\mathrm{v}}$, while the in situ data increase only to $230 \mathrm{ppt}_{\mathrm{v}}$. During the last period of the flight, simulated and measured data are again in good agreement. Here the mixing ratios from EMAC are in the range of 110-157 $\mathrm{ppt}_{\mathrm{v}}$, while the measured data are in the range of 128-203 ppt $\mathrm{v}$. This steep drop of $\mathrm{H}_{2} \mathrm{O}_{2}{ }^{\text {EMAC }}$ might arise due to a change in the flight altitude since between 08:01 and 08:06 UTC the aircraft changed from a flight level at $11700 \mathrm{~m}$ to one aloft at $13900 \mathrm{~m}$.

In addition to EMAC simulations, Fig. 3 also shows the calculated $\mathrm{H}_{2} \mathrm{O}_{2}{ }^{\mathrm{PSS}}$ obtained from Eq. (15). Observed and PSS values for $\mathrm{H}_{2} \mathrm{O}_{2}$ mixing ratios agree very well, with a median deviation of $42 \mathrm{ppt}_{\mathrm{v}}$, well within the combined uncertainties of measured data (25\%) and PSS simulations (45\%).

In Fig. 4 the time series of $\mathrm{H}_{2} \mathrm{O}_{2}{ }^{\text {obs }}$, MHP ${ }^{\mathrm{PSS}}$, and $\mathrm{UHP}^{\mathrm{PSS}}$ mixing ratios are shown (5 min means). In the beginning of the flight, $\mathrm{MHP}^{\mathrm{PSS}}$ is the dominant organic hydroperoxide. The mixing ratios are in the range of $140-341 \mathrm{ppt}_{\mathrm{v}}$, similar to those of $\mathrm{H}_{2} \mathrm{O}_{2}$ obs $\left(143-337 \mathrm{ppt}_{\mathrm{v}}\right.$ ). UHP ${ }^{\mathrm{PSS}}$ mixing ratios are in the range of 24-162 $\mathrm{ppt}_{\mathrm{v}}$, with a mean of $89 \mathrm{ppt}_{\mathrm{v}}$. Later during the flight, $\mathrm{UHP}^{\mathrm{PSS}}$ are the dominant hydroperoxides in air masses inside the AMA originating from India. Here we found $\mathrm{UHP}^{\mathrm{PSS}}$ mixing ratios up to $275 \mathrm{ppt}_{\mathrm{v}}$. The $\mathrm{H}_{2} \mathrm{O}_{2}$ obs mixing ratios show a similar temporal pattern and mixing ratio levels to those of UHP ${ }^{\mathrm{PSS}}$ over the Arabian Sea and the Arabian Peninsula, with values in the range of $140-243 \mathrm{ppt}_{\mathrm{v}}$. $\mathrm{MHP}^{\mathrm{PSS}}$ mixing ratios are much lower (62-130 $\mathrm{ppt}_{\mathrm{v}}$, median of $72 \mathrm{ppt}_{\mathrm{v}}$ ) in this area. During this part of the flight, the similarity in the time series of acetone and UHP ${ }^{\mathrm{PSS}}$ (Fig. 5) indicates either similar source regions for both species or the role of acetone as a precursor for the UHP ${ }^{\mathrm{PSS}}$ in AMA-influenced air masses. From 06:20 UTC onwards an increase in both compounds is observed until 07:45 UTC, followed by a steep drop, with a minimum at 08:17 UTC. The UHPPSS and acetone mixing ratios in this part of the flight are strongly correlated (Fig. 6), with a slope of $0.19 \pm 0.02\left(\mathrm{ppb}_{\mathrm{v}} \mathrm{ppb}_{\mathrm{v}}{ }^{-1}\right)$ and an offset of $(-0.003 \pm 0.02) \mathrm{ppb}_{\mathrm{v}}$. The regression coefficient $R^{2}$ is very high $(0.82)$. For $\mathrm{H}_{2} \mathrm{O}_{2}{ }^{\text {obs }}$, MHP ${ }^{\mathrm{PSS}}$, and $\mathrm{ROOH}^{\text {obs }}$ the correlation is not that strong, with slopes of $-0.02 \pm 0.02\left(\mathrm{ppb}_{\mathrm{v}} \mathrm{ppb}_{\mathrm{v}}{ }^{-1}\right),-0.07 \pm 0.01\left(\mathrm{ppb}_{\mathrm{v}} \mathrm{ppb}_{\mathrm{v}}{ }^{-1}\right)$, and $0.13 \pm 0.03\left(\mathrm{ppb}_{\mathrm{v}} \mathrm{ppb}_{\mathrm{v}}{ }^{-1}\right)$, respectively, and offsets of $(0.21 \pm 0.02) \mathrm{ppb}_{\mathrm{v}},(0.12 \pm 0.01) \mathrm{ppb}_{\mathrm{v}}$, and $(0.11 \pm 0.03) \mathrm{ppb}_{\mathrm{v}}$ (Fig. 6). The relation between ROOH mixing ratios and an air mass age tracer based on the ratio between $[\mathrm{NO}]$ and $\left[\mathrm{NO}_{y}\right]$ shows higher values of $\mathrm{ROOH}$ at smaller ratios, representing older or more processed air masses (Fig. 7) since the highest $\mathrm{ROOH}$ mixing ratios $\left(>200 \mathrm{ppt}_{\mathrm{v}}\right.$ ) are found at the lowest $[\mathrm{NO}] /\left[\mathrm{NO}_{y}\right]$ ratios (all $<0.19$ ). Thus, most of the observed $\mathrm{ROOH}$ were measured in aged air masses transported within the anticyclone. The correlation with UHP ${ }^{\mathrm{PSS}}$ shows that this effect is mainly due to UHP ${ }^{\mathrm{PSS}}$. For $\mathrm{H}_{2} \mathrm{O}_{2}{ }^{\text {obs }}$ there are also some higher mixing ratios for high $[\mathrm{NO}]-$ to- $\left[\mathrm{NO}_{y}\right]$ mixing ratios and thus fresher air (Fig. 7).

\subsection{Results for the entire campaign}

To extend the analysis to the entire campaign, Fig. 8 shows all flight tracks in the UT during OMO. The color code represents observed mixing ratios of $\mathrm{H}_{2} \mathrm{O}_{2}{ }^{\text {obs }}$, MHPPS , and 


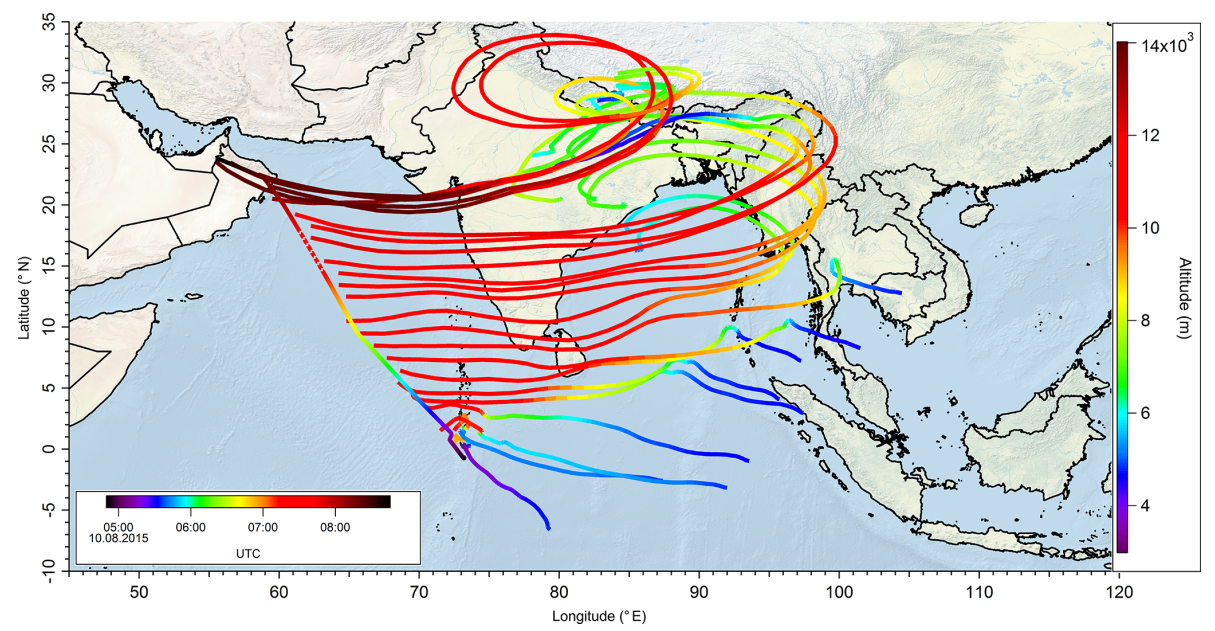

Figure 2. Track of Flight 17 (dotted black line) and calculated $10 \mathrm{~d}$ back trajectories (lines colored as a function of altitude) to show the origin of sampled air masses during the flight.

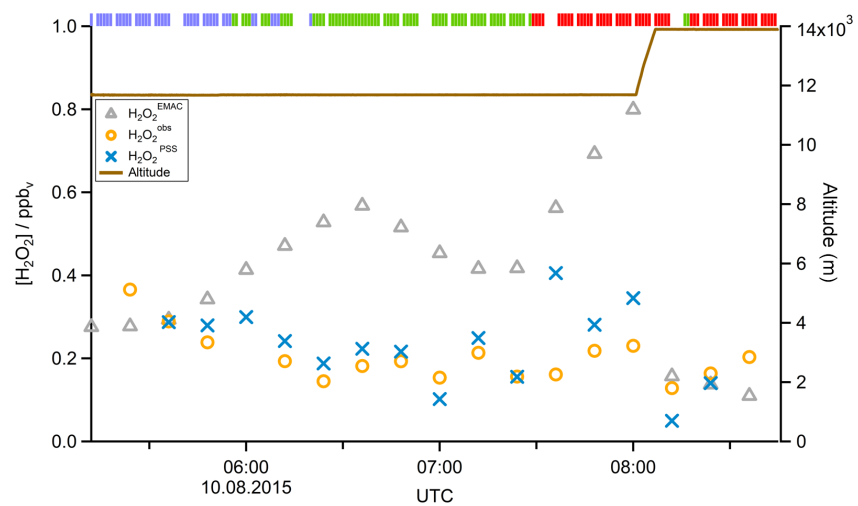

Figure 3. Time series of $\mathrm{H}_{2} \mathrm{O}_{2}$ obs (orange circles), $\mathrm{H}_{2} \mathrm{O}_{2}$ PSS (blue crosses), and $\mathrm{H}_{2} \mathrm{O}_{2}$ EMAC (gray triangles) mixing ratios for Flight 17. The brown line shows the altitude; the colored bar on top indicates the origin of air masses according to the methane mixing ratio classification: for SH blue, NH green, and AMA red.

$\mathrm{UHP}^{\mathrm{PSS}}$ varying from low (purple) to high values (red). Histograms for the whole campaign of $\mathrm{H}_{2} \mathrm{O}_{2}{ }^{\text {obs }}$ mixing ratios as well as inferred $\mathrm{MHP}^{\mathrm{PSS}}$ and $\mathrm{UHP}^{\mathrm{PSS}}$ mixing ratios are presented in Fig. 9. Here only data from the UT $(<300 \mathrm{hPa}$, which corresponds to altitudes $>9 \mathrm{~km}$ ) were included in the analysis. Mixing ratios for all species were further differentiated by methane levels such that data in air masses with $\mathrm{CH}_{4}$ mixing ratios above the threshold of $1879.8 \mathrm{ppb}_{\mathrm{v}}$ were classified as AMA-influenced, while air masses with $\mathrm{CH}_{4}$ mixing ratios between $1820 \mathrm{ppb}_{\mathrm{v}}$ and $1879.8 \mathrm{ppb}_{\mathrm{v}}$ were classified as $\mathrm{NH}$ background and those with $\mathrm{CH}_{4}<1820 \mathrm{ppb}_{\mathrm{v}}$ as SH following Tomsche et al. (2019). Figure 9a indicates that $\mathrm{H}_{2} \mathrm{O}_{2}{ }^{\text {obs }}$ mixing ratios are most abundant at values of $70-90 \mathrm{ppt}_{\mathrm{v}}$ in $\mathrm{NH}$ background air masses (green); 130 to $270 \mathrm{ppt}_{\mathrm{v}}$ with three notable peaks at 180-190, 210-220, and 250-270 $\mathrm{ppt}_{\mathrm{v}}$ in SH air masses (blue); and 150-170 $\mathrm{ppt}_{\mathrm{v}}$ in

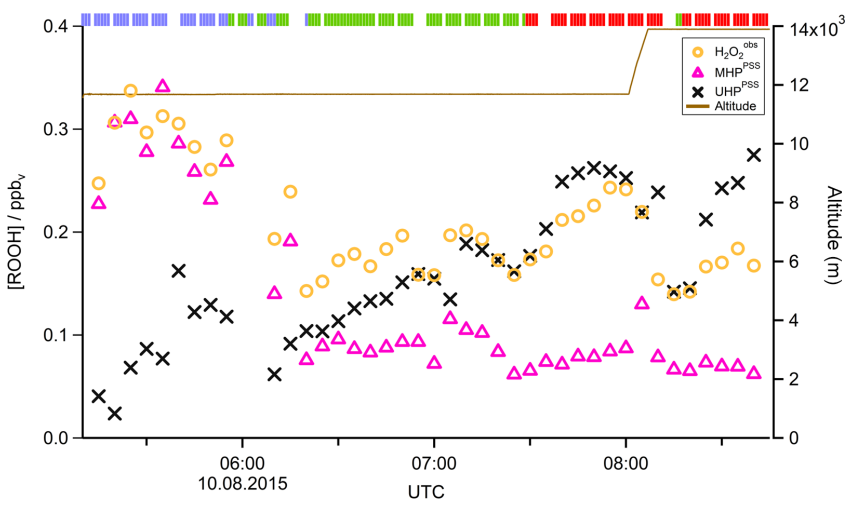

Figure 4. Time series of hydroperoxide mixing ratios during Flight 17. The mixing ratios of $\mathrm{H}_{2} \mathrm{O}_{2}$ obs (orange circles), MHP ${ }^{P S S}$ (pink triangles), and UHPPSS (black crosses) are shown. The brown line shows the altitude; the colored bar on top indicates the origin of air masses according to the methane mixing ratio classification: for $\mathrm{SH}$ blue, NH green, and AMA red.

AMA-influenced air masses (red). The medians are $115 \mathrm{ppt}_{\mathrm{v}}$ for the $\mathrm{NH}$ background, $211 \mathrm{ppt}_{\mathrm{v}}$ for the $\mathrm{SH}$, and $167 \mathrm{ppt}_{\mathrm{v}}$ for the AMA, indicating an excess of $52 \mathrm{ppt}_{\mathrm{v}}$ in AMA-influenced air masses compared to the $\mathrm{NH}$ background, while in the $\mathrm{SH}$ the $\mathrm{H}_{2} \mathrm{O}_{2}{ }^{\text {obs }}$ mixing ratio is twice as high as the NH background. For MHP ${ }^{\mathrm{PSS}}$ (Fig. 9b) the frequency distribution in the NH background shows a maximum at $30-40 \mathrm{ppt}_{\mathrm{v}}$ (green). For AMA-influenced air a sharp maximum at $50-70 \mathrm{ppt}_{\mathrm{v}}$ (red) is found. Air masses from the SH exhibit a rather flat distribution, with a maximum at values of $40-50 \mathrm{ppt}_{\mathrm{v}}$ and a median of $152 \mathrm{ppt}_{\mathrm{v}}$ (blue). With median mixing ratios of 70 and $64 \mathrm{ppt}_{\mathrm{v}}$, we found only slightly higher mixing ratios for AMA-influenced air masses in comparison to the NH background. For UHP ${ }^{\text {PSS }}$ (Fig. 9c) we again found a flat distribution of mixing ratios in the $\mathrm{SH}$ (blue), with a maximum at val- 


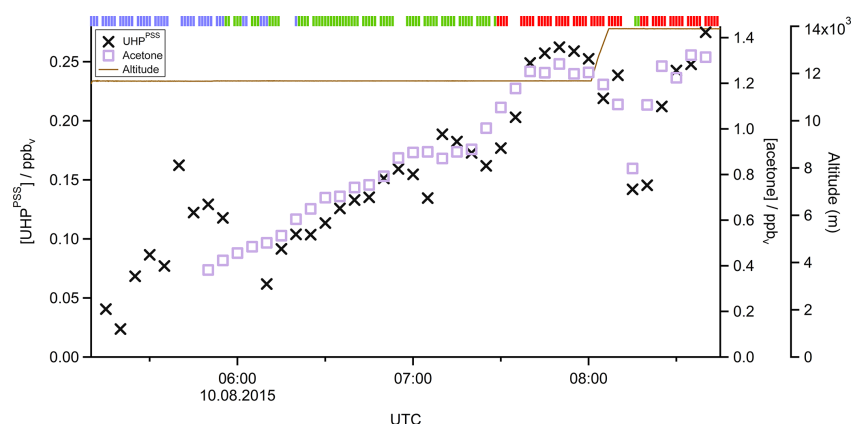

Figure 5. Time series of UHPPSS (black crosses) and acetone (purple squares) mixing ratios during Flight 17 . The brown line shows the altitude, the colored bar on top indicates the origin of air masses according to the methane mixing ratio classification: for $\mathrm{SH}$ blue, NH green, and AMA red.

ues of 140-150 $\mathrm{ppt}_{\mathrm{v}}$ and a median of $129 \mathrm{ppt}_{\mathrm{v}}$. The maximum in the frequency distribution for $\mathrm{NH}$ background conditions is found at 70-90 $\mathrm{ppt}_{\mathrm{v}}$ (green), while in AMA-influenced air masses it was significantly higher, with $210-230 \operatorname{ppt}_{\mathrm{v}}(\mathrm{red})$. Thus, mixing ratios of $\mathrm{UHP}^{\mathrm{PSS}}$ are approximately $2-3$ times higher in the AMA outflow than in the NH background. This is also represented in the medians of $210 \mathrm{ppt}_{\mathrm{v}}$ in the AMA and $89 \mathrm{ppt}_{\mathrm{v}}$ in the $\mathrm{NH}$ background.

In the analysis of Flight 17 we found a strong correlation between UHP ${ }^{\mathrm{PSS}}$ and acetone (Fig. 6) and an increase in $\mathrm{UHP}^{\mathrm{PSS}}$ at the highest air mass ages, represented by low $[\mathrm{NO}] /\left[\mathrm{NO}_{y}\right]$ (Fig. 7). Extension of this analysis to all observations in the upper troposphere obtained during OMO yields similar results for the relation between $\mathrm{UHP}^{\mathrm{PSS}}, \mathrm{ROOH}^{\mathrm{obs}}$, and $\mathrm{H}_{2} \mathrm{O}_{2}{ }^{\text {obs }}$ and acetone (Fig. 10). Enhanced mixing ratios of hydroperoxides are typically associated with enhanced acetone mixing ratios, especially for UHP ${ }^{\mathrm{PSS}}$. A simple calculation of the production of MHP out of the photolysis of acetone and the reaction of acetaldehyde (from EMAC) with $\mathrm{OH}$ shows that per day approximately $40 \mathrm{ppt}_{\mathrm{v}}$ MHP can be formed within the AMA. The lifetime of MHP was calculated to be around $1.5 \mathrm{~d}$. Thus not all of the UHPPSS in the AMA (median $210 \mathrm{ppt}_{\mathrm{v}}$ ) can be accounted for MHP that was chemically produced from VOCs in the AMA. The scatterplots of the hydroperoxides vs. $[\mathrm{NO}] /\left[\mathrm{NO}_{y}\right]$ for the whole data set show no clear correlation with a large spread of hydroperoxide mixing ratios at the lowest $[\mathrm{NO}] /\left[\mathrm{NO}_{y}\right]$ ratios, representing the oldest, i.e., chemically most processed, air masses (Fig. 11).

\subsection{1 $\quad \mathrm{H}_{2} \mathrm{O}_{2}$ steady-state calculation}

A scatterplot of the results from the $\mathrm{H}_{2} \mathrm{O}_{2}{ }^{\mathrm{PSS}}$ based on observed $\mathrm{HO}_{x}$ data in the UT (Eq. 15) is shown in Fig. 12. The dotted black line shows the $1: 1$ line; the dashed green lines represent the $2: 1$ and $1: 2$ relations. It is obvious that the comparison is affected by a rather large offset of approximately $350 \mathrm{ppt}_{\mathrm{v}}$ in the observations that is not accounted for
Table 1. Comparison of $\mathrm{H}_{2} \mathrm{O}_{2}$ mixing ratios in the upper troposphere from observations and PSS calculations.

\begin{tabular}{llr}
\hline Method & Median & {$\left[\mathrm{H}_{2} \mathrm{O}_{2}\right]\left(\mathrm{ppt}_{\mathrm{v}}\right)$} \\
\hline PSS & Median & 15 \\
& Range & LOD-657 \\
& avg $\pm \mathrm{SD}$ & $61 \pm 101$ \\
\hline Obs & Median & 150 \\
& Range & LOD-530 \\
& avg $\pm \mathrm{SD}$ & $165 \pm 91$ \\
\hline
\end{tabular}

in the steady-state calculations. The regression coefficient $R^{2}$ is 0.26 . Most of the $\mathrm{H}_{2} \mathrm{O}_{2}{ }^{\text {PSS }}$ mixing ratios (75\%) vary between 0 and $65 \mathrm{ppt}_{\mathrm{v}}$, with a median value of $15 \mathrm{ppt}_{\mathrm{v}}$, while the $\mathrm{H}_{2} \mathrm{O}_{2}{ }^{\text {obs }}$ mixing ratios extend over a larger range, mainly between 10 and $210 \mathrm{ppt}_{\mathrm{v}}$, with a median of $150 \mathrm{ppt}_{\mathrm{v}}$ and thus 10 times higher than for steady-state, indicating that more than $80 \%$ of all points in the correlation are outside the range of uncertainty. This can also be seen in the histograms in Fig. 13. Table 1 shows the statistical comparison of both data sets. The discrepancy between $\mathrm{H}_{2} \mathrm{O}_{2}{ }^{\text {obs }}$ and $\mathrm{H}_{2} \mathrm{O}_{2}{ }^{\text {PSS }}$ shows that the local PSS does not account for all main contributions of $\mathrm{H}_{2} \mathrm{O}_{2}$ even though all chemical reactions are included. Thus transport phenomena like deep convection seem to play a key role (see Sect. 4.3.3).

\subsubsection{Comparison to EMAC}

Figure 14 shows histograms for the comparison between $\mathrm{H}_{2} \mathrm{O}_{2}{ }^{\text {obs }}$, MHPPS, and UHP ${ }^{P S S}$ with EMAC simulations. Median $\mathrm{H}_{2} \mathrm{O}_{2}{ }^{\text {EMAC }}$ values are similar for NH background $\left(66 \mathrm{ppt}_{\mathrm{v}}\right.$ ) and AMA (71 ppt $\mathrm{v}_{\mathrm{v}}$ ) conditions (Table 2), while $\mathrm{H}_{2} \mathrm{O}_{2}$ obs indicate an enhancement of +64 ppt $_{\mathrm{v}}$ in the AMA relative to the $\mathrm{NH}$ background. For the $\mathrm{SH}$ the model-simulated $\mathrm{H}_{2} \mathrm{O}_{2}$ EMAC $\left(272 \mathrm{ppt}_{\mathrm{v}}\right.$ ) mixing ratios are 4 times higher than in the $\mathrm{NH}$ background $\left(66 \mathrm{ppt}_{\mathrm{v}}\right)$, while the $\mathrm{H}_{2} \mathrm{O}_{2}$ obs mixing ratios only show a median increase by roughly a factor of 2 (100 to $211 \mathrm{ppt}_{\mathrm{v}}$; Table 2).

In general EMAC tends to strongly underestimate total hydroperoxide in all air masses by a factor of 5-10. MHPEMAC mixing ratios are mainly lower than $50 \mathrm{ppt}_{\mathrm{v}}$ for background and AMA, while MHP ${ }^{\mathrm{PSS}}$ ranges from LOD$140 \mathrm{ppt}_{\mathrm{v}}$. Again the model simulates the highest MHPEMAC mixing ratios in the $\mathrm{SH}$, with values up to $502 \mathrm{ppt}_{\mathrm{v}}$ compared to up to $346 \mathrm{ppt}_{\mathrm{v}}$ in the MHPPSS calculations. Similar as for $\mathrm{H}_{2} \mathrm{O}_{2}{ }^{\mathrm{EMAC}}$, medians of MHP ${ }^{\mathrm{EMAC}}$ for NH background and AMA conditions show very small differences (11 and $13 \mathrm{ppt}_{\mathrm{v}}$, respectively; Table 2), while slightly higher differences were found for UHP ${ }^{\mathrm{EMAC}}$ in the AMA (64 and $70 \mathrm{ppt}_{\mathrm{v}}$, respectively). In the simulations, southern hemispheric MHP ${ }^{\mathrm{EMAC}}$ mixing ratios are almost 10 times higher than $\mathrm{NH}$ background values (116 and $11 \mathrm{ppt}_{\mathrm{v}}$, respectively) compared to 2 to 3 times higher in the observations. 

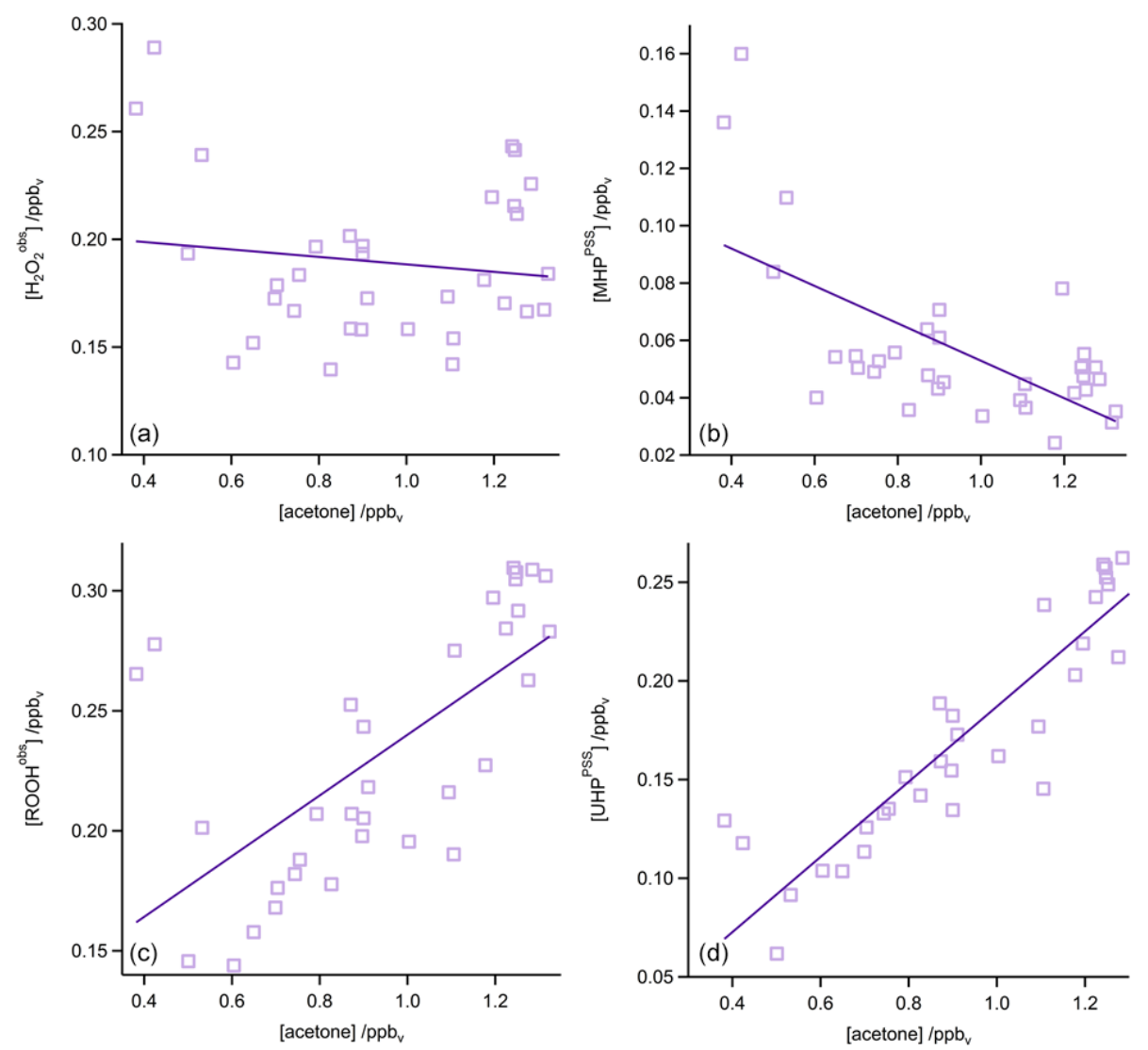

Figure 6. Scatterplots of measured acetone and $\mathrm{H}_{2} \mathrm{O}_{2}{ }^{\text {obs }}(\mathbf{a}), \mathrm{MHP}^{\mathrm{PSS}}$ (b), $\mathrm{ROOH}^{\text {obs }}$ (c), and $\mathrm{UHP}^{\mathrm{PSS}}$ (d) during Flight 17. The dark purple lines represent the least-orthogonal-distance fits with regression coefficients $R^{2}$ of $0.02,0.41,0.43$, and 0.82 .
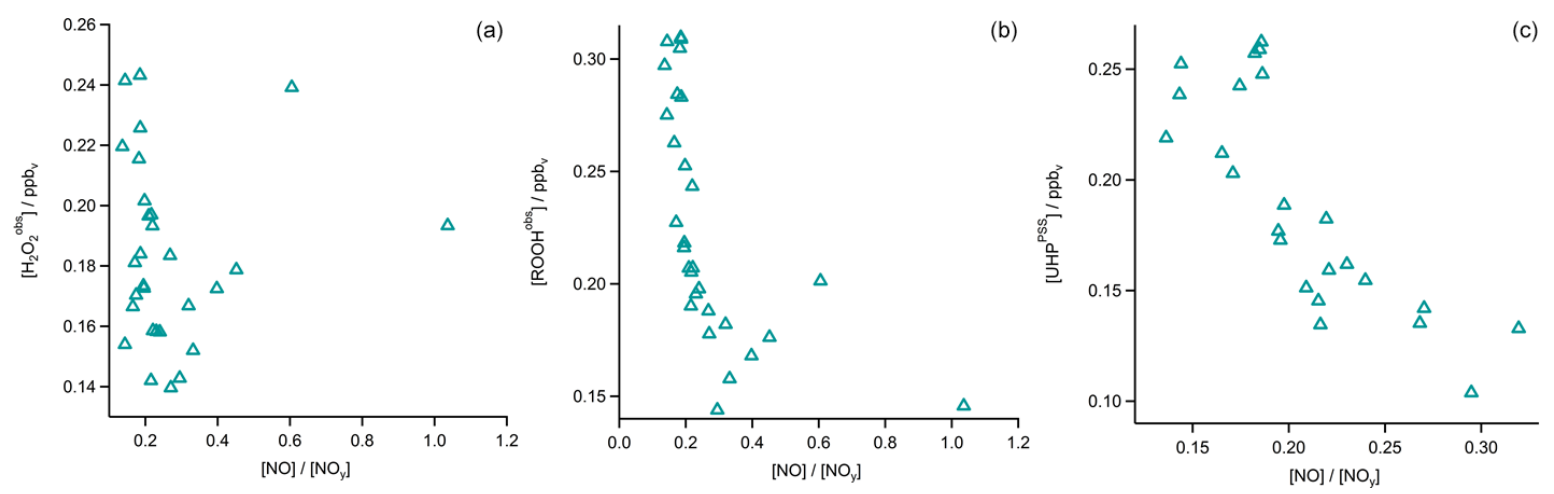

Figure 7. Scatterplots of $\mathrm{H}_{2} \mathrm{O}_{2}{ }^{\text {obs }}(\mathbf{a}), \mathrm{ROOH}^{\mathrm{obs}}(\mathbf{b})$, and $\mathrm{UHP}^{\mathrm{PSS}}$ (c) and $\mathrm{NO} / \mathrm{NO}_{y}$ ratio during Flight 17.

Data for UHPEMAC in the model are calculated from the sum of simulated ethyl hydroperoxide (EHP) and peroxyacetic acid (PAA), which, according to the model, are the only nonmethyl organic hydroperoxides in the free troposphere with nonzero mixing ratios. UHP ${ }^{E M A C}$ mixing ratios range from 1 to $238 \mathrm{ppt}_{\mathrm{v}}$ in the $\mathrm{NH}$ background, 1 to $259 \mathrm{ppt}_{\mathrm{v}}$ in the AMA, and 1 to $132 \mathrm{ppt}_{\mathrm{v}}$ in the SH. UHP ${ }^{\mathrm{PSS}}$ based on the observations indicate lowest mixing ratios in the NH background (LOD-261 ppt $_{\mathrm{v}}$ ), while in the AMA and the SH the ranges are quite similar $\left(80-311 \mathrm{ppt}_{\mathrm{v}}\right.$ and LOD$334 \mathrm{ppt}_{\mathrm{v}}$ ). A comparison of median values emphasizes the large difference between model simulations and observationbased estimates. In the NH background, the median UHP PSS mixing ratio from the observations is $70 \mathrm{ppt}_{\mathrm{v}}$ higher than EMAC simulations (78 and $8 \mathrm{ppt}_{\mathrm{v}}$, respectively). In the AMA the difference is even larger, with about $200 \mathrm{ppt}_{\mathrm{v}}$ higher $\mathrm{UHP}^{\mathrm{PSS}}$ levels compared to the EMAC simulations. The 
Table 2. Comparison of $\mathrm{H}_{2} \mathrm{O}_{2}$, MHP and UHP mixing ratios in the upper troposphere from EMAC, measurements and PSS calculations.

\begin{tabular}{|c|c|c|c|c|c|c|c|c|c|}
\hline \multirow[t]{2}{*}{ Region } & \multirow[t]{2}{*}{ Median } & \multicolumn{2}{|c|}{$\left[\mathrm{H}_{2} \mathrm{O}_{2}\right]\left(\mathrm{ppt}_{\mathrm{v}}\right)$} & \multicolumn{2}{|c|}{$[\mathrm{MHP}]\left(\mathrm{ppt}_{\mathrm{V}}\right)$} & \multicolumn{2}{|c|}{$[\mathrm{UHP}]\left(\mathrm{ppt}_{\mathrm{V}}\right)$} & \multicolumn{2}{|c|}{$[\mathrm{ROOH}]\left(\mathrm{ppt}_{\mathrm{v}}\right)$} \\
\hline & & EMAC & Obs & EMAC & PSS & EMAC & PSS & EMAC & Obs \\
\hline \multirow[t]{3}{*}{$\mathrm{NH}$} & Median & 66 & 100 & 11 & 64 & 8 & 78 & 18 & 135 \\
\hline & Range & $6-576$ & 20-301 & $2-408$ & $21-202$ & $1-238$ & LOD-261 & $3-458$ & $18-439$ \\
\hline & $\operatorname{Avg} \pm \mathrm{SD}$ & $102 \pm 110$ & $110 \pm 53$ & $28 \pm 58$ & $75 \pm 42$ & $18 \pm 31$ & $103 \pm 77$ & $46 \pm 79$ & $151 \pm 82$ \\
\hline \multirow[t]{3}{*}{ AMA } & Median & 71 & 164 & 13 & 70 & 12 & 208 & 23 & 244 \\
\hline & Range & $8-714$ & $46-446$ & $2-216$ & $37-220$ & $1-259$ & $80-311$ & $2-445$ & $86-364$ \\
\hline & $\operatorname{Avg} \pm \mathrm{SD}$ & $84 \pm 92$ & $167 \pm 69$ & $18 \pm 28$ & $92 \pm 49$ & $18 \pm 34$ & $199 \pm 59$ & $34 \pm 58$ & $245 \pm 59$ \\
\hline \multirow[t]{3}{*}{$\mathrm{SH}$} & Median & 272 & 211 & 116 & 152 & 33 & 122 & 174 & 236 \\
\hline & Range & $15-409$ & $85-510$ & $2-502$ & $40-346$ & $1-132$ & LOD-334 & $2-547$ & $9-446$ \\
\hline & $\operatorname{Avg} \pm \mathrm{SD}$ & $272 \pm 68$ & $238 \pm 105$ & $155 \pm 125$ & $191 \pm 95$ & $42 \pm 24$ & $125 \pm 102$ & $197 \pm 129$ & $232 \pm 84$ \\
\hline
\end{tabular}
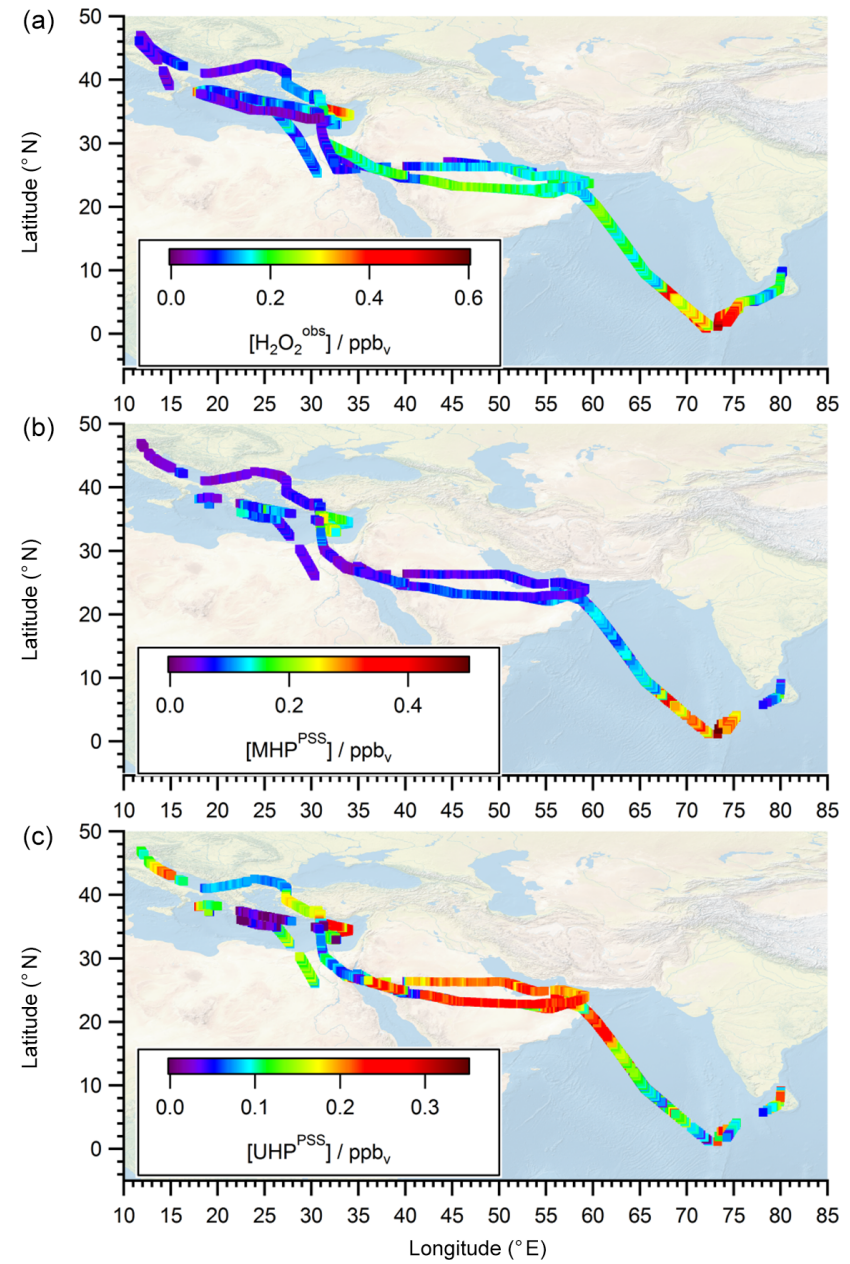

Figure 8. All flight positions in the upper troposphere $(p<$ $300 \mathrm{hPa}$ ) during $\mathrm{OMO}$ as a function of (a) $\mathrm{H}_{2} \mathrm{O}_{2}{ }^{\text {obs }}$, (b) MHPPSS , and (c) $\mathrm{UHP}^{\mathrm{PSS}}$. smallest difference, with $89 \mathrm{ppt}_{\mathrm{v}}$, was found for the SH (Table 2).

\subsubsection{Longitudinal gradients}

So far discussions of different air masses have been based on measurements of methane, subdividing the observations into NH background, AMA, and SH data. Tomsche et al. (2019) have shown that longitudinal gradients are found in the AMA over the Arabian Peninsula. Observations in the west are often near the edge of the anticyclone, while observations towards the east are closer to its center. In Fig. 16, observations, steady-state calculations, and EMAC simulations for upper tropospheric $(9-15 \mathrm{~km}) \mathrm{H}_{2} \mathrm{O}_{2}$ are displayed as a function of longitude from west to east $\left(20-30^{\circ} \mathrm{N}, 36-60^{\circ} \mathrm{E}\right.$; according to the red box in Fig. 15). To identify gradients, the data are subdivided into bins of $2^{\circ}$ longitude. The observations (orange) show roughly a $100 \%$ increase in $\mathrm{H}_{2} \mathrm{O}_{2}{ }^{\text {obs }}$ from west to east (90 to $175 \mathrm{ppt}_{\mathrm{v}}$ ), similar to simulation with EMAC (black), although absolute mixing ratio levels in $\mathrm{H}_{2} \mathrm{O}_{2}$ EMAC are smaller (61 to $121 \mathrm{ppt}_{\mathrm{v}}$ ). Contrary to these observed gradients, $\mathrm{H}_{2} \mathrm{O}_{2}$ PSS mixing ratios based on HORUS data (blue) do not vary with longitude, except for the last two bins. The steady-state calculations are based exclusively on observed concentrations of $\mathrm{HO}_{2}$ and $\mathrm{OH}$ radicals and thus yield only the net photochemical production, while the EMAC simulations and the observations will also account for vertical and horizontal advection from upwind source regions. Previous studies show inconsistent results. Snow et al. (2007) and Barth et al. (2016) for example both show that $\mathrm{H}_{2} \mathrm{O}_{2}$ is depleted in convective outflow compared to background upper troposphere. In contrast, other studies found that deep convection can be a source of $\mathrm{H}_{2} \mathrm{O}_{2}$ in the upper troposphere (e.g., Jaeglé et al., 1997; Prather and Jacob, 1997; Mari et al., 2003; Bozem et al., 2017). Similarly, convection over India during the summer monsoon is a potential source of excess $\mathrm{H}_{2} \mathrm{O}_{2}$ in the upper troposphere. With a photochemical lifetime of several days, this excess in $\mathrm{H}_{2} \mathrm{O}_{2}$ reaches the western AMA, giving rise to the observed and model-simulated lon- 


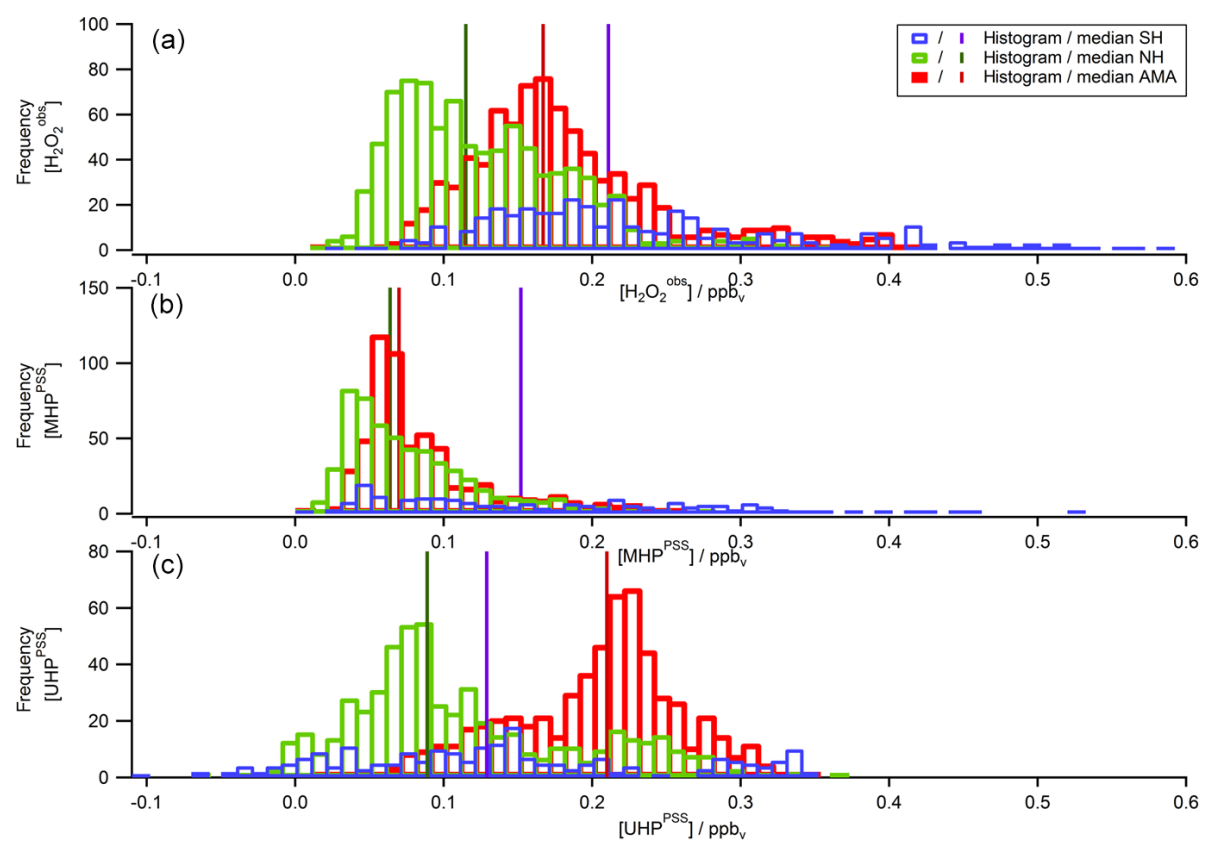

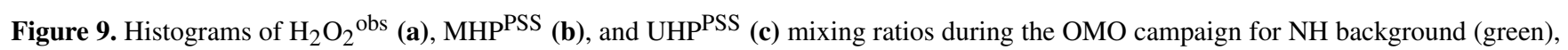
SH (blue), and AMA (red) air masses.
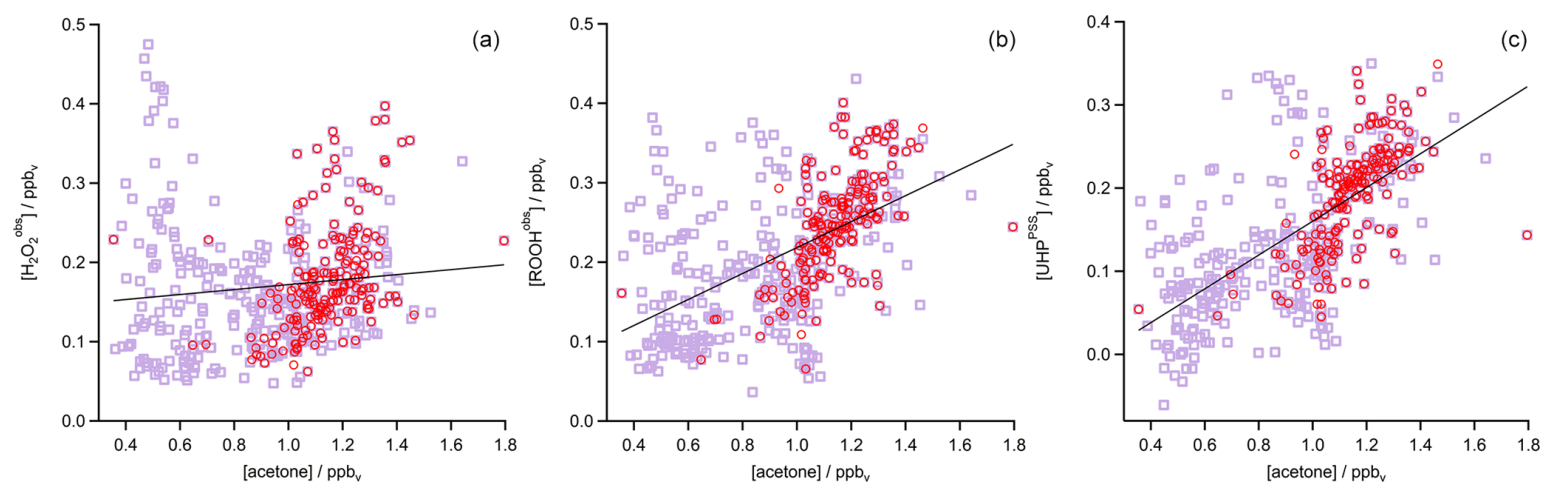

Figure 10. Scatterplots of acetone and $\mathrm{H}_{2} \mathrm{O}_{2}$ obs (a), $\mathrm{ROOH}^{\text {obs }}$ (b), and UHP ${ }^{\mathrm{PSS}}$ (c) in the UT (purple squares) and especially in the AMA (red circles). The black lines represent the least-orthogonal-distance fit with linear regression coefficients $R^{2}$ of $0.01\left(\mathrm{H}_{2} \mathrm{O}_{2}{ }^{\mathrm{obs}}\right), 0.27$ $\left(\mathrm{ROOH}^{\mathrm{obs}}\right)$, and $0.41\left(\mathrm{UHP}^{\mathrm{PSS}}\right)$.

gitudinal gradients. Since the steady-state calculations do not account for transport, this can explain the rather large deviation of 144-164 $\mathrm{ppt}_{\mathrm{v}}$ (between 51 and $57^{\circ}$ ) from the observations. Differences between observation and EMAC simulation could potentially arise due to uncertainties in the scavenging efficiency for $\mathrm{H}_{2} \mathrm{O}_{2}$ as the chemistry does not seem to be a dominant cause of uncertainty.

Similar longitudinal gradients are also observed for measured total organic hydroperoxides $\left(\mathrm{ROOH}^{\mathrm{obs}}\right.$; green asterisks in Fig. 17), inferred UHP ${ }^{\mathrm{PSS}}$ (black); and total $\mathrm{ROOH}^{\mathrm{EMAC}}$ (blue). Steady-state calculations of MHP ${ }^{\mathrm{PSS}}$ (pink) and simulations of MHP ${ }^{\mathrm{EMAC}}$ (yellow) show either no or only weak longitudinal gradients. Assuming that MHP is also enhanced in the outflow of deep convection (Mari et al., 2000; Barth et al., 2016), at least part of the enhancement in $\mathrm{ROOH}^{\text {obs }}$ (and thus inferred UHP ${ }^{\mathrm{PSS}}$ ) could be due to advected MHP.

\subsection{Discussion}

To our knowledge we present the first observations of $\mathrm{H}_{2} \mathrm{O}_{2}$ and $\mathrm{ROOH}$ mixing ratios in the Asian monsoon anticyclone. Previous studies have been mainly focused on the northern hemispheric upper troposphere. Several aircraft campaigns including peroxide measurements were performed over North America. They are summarized in Snow et al., 2007): the SONEX campaign took place in fall 1997 in the UT and yielded mean values of $120 \mathrm{ppt}_{\mathrm{v}}$ for $\mathrm{H}_{2} \mathrm{O}_{2}$ and 

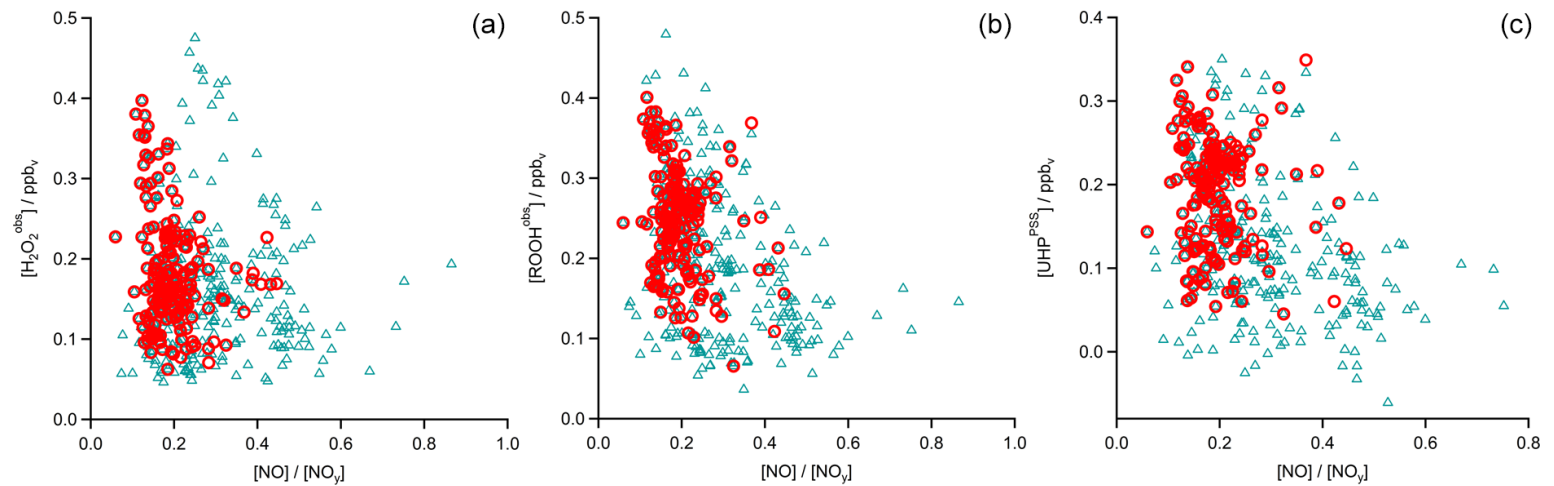

Figure 11. Scatterplots of $\mathrm{NO} / \mathrm{NO}_{y}$ and $\mathrm{H}_{2} \mathrm{O}_{2}{ }^{\text {obs }}(\mathbf{a}), \mathrm{ROOH}^{\mathrm{obs}}(\mathbf{b})$, and $\mathrm{UHP}^{\mathrm{PSS}}$ (c) in the UT (blue triangles) and especially in the AMA (red circles).

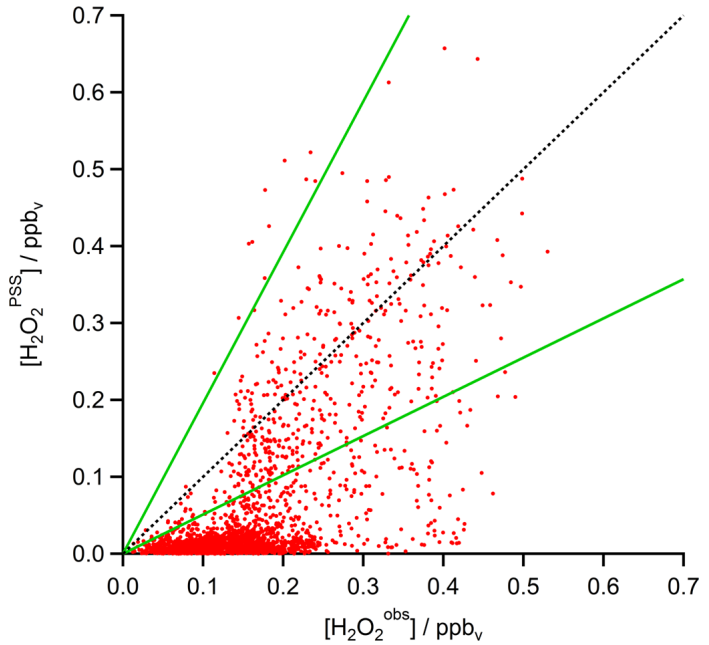

Figure 12. Scatterplot of $\mathrm{H}_{2} \mathrm{O}_{2}$ obs and $\mathrm{H}_{2} \mathrm{O}_{2}{ }^{\mathrm{PSS}}$ mixing ratios (red) with the $1: 1$ (black), $1: 2$, and $2: 1$ (both green) lines.

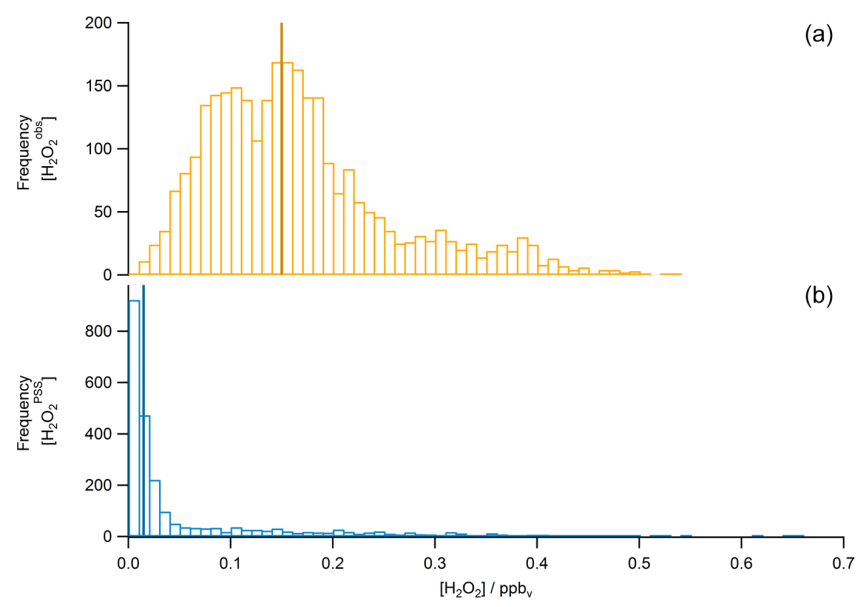

Figure 13. Histograms of $\mathrm{H}_{2} \mathrm{O}_{2}{ }^{\text {obs }}$ (a) and $\mathrm{H}_{2} \mathrm{O}_{2}{ }^{\mathrm{PSS}}$ (b) mixing ratios (bars) and the associated medians (lines).
$50 \mathrm{ppt}_{\mathrm{v}}$ for MHP (medians: 80 and $30 \mathrm{ppt}_{\mathrm{v}}$, respectively). The TOPSE campaign in winter/spring 2000 probed the middle troposphere, yielding median $\mathrm{H}_{2} \mathrm{O}_{2}$ and MHP mixing ratios of $150 \mathrm{ppt}_{\mathrm{v}}$ for both species. During the INTEX-NA campaign in summer 2004, observed median mixing ratios at altitudes of 6-10 km were about $400 \mathrm{ppt}_{\mathrm{v}}$ for $\mathrm{H}_{2} \mathrm{O}_{2}$ and $200 \mathrm{ppt}_{\mathrm{v}}$ for MHP. A comparison with our results (Table 2) shows that we found similar mixing ratios as in SONEX in the northern hemispheric background of 115 and $64 \mathrm{ppt}_{\mathrm{v}}$ for $\mathrm{H}_{2} \mathrm{O}_{2}$ and MHP, respectively. Mixing ratios for both species reported for TOPSE and INTEX-NA are slightly higher than ours, which may be related to the lower altitude range of 6 $10 \mathrm{~km}$ (in comparison to $>9 \mathrm{~km}$ for OMO) in these studies. Previous observations have shown that $\mathrm{H}_{2} \mathrm{O}_{2}$ and $\mathrm{MHP}$ show the highest mixing ratios at altitudes between 2 and $5 \mathrm{~km}$ followed by a sharp decrease towards higher altitudes (see e.g., Daum et al., 1990; Heikes, 1992; Weinstein-Lloyd et al., 1998; Snow, 2003; Snow et al., 2007; Klippel et al., 2011).

Heikes et al. (1996) associated enhanced $\mathrm{H}_{2} \mathrm{O}_{2}$ mixing ratios above $5 \mathrm{~km}$ in the North Pacific of the Asian coast $\left(30^{\circ} \mathrm{N}\right)$ with outflow from Typhoon Mireille (Heikes et al., 1996). These observations were made close to the source region for the AMA-influenced air masses described here (see back trajectories in the case study of Flight 17; Fig. 2 or Tomsche et al., 2019). For MHP Heikes et al. (1996) found mixing ratios of 250-500 $\mathrm{ppt}_{\mathrm{v}}$ in the southern longitudinal section above $5 \mathrm{~km}$, similar to median mixing ratios of $152 \mathrm{ppt}_{\mathrm{v}}$ for MHP in SH air masses in the UT found in this study.

Although the mixing ratios observed during this study are similar to previous observations in the upper troposphere, one striking result is that a state-of-the-art global circulation model (EMAC) and a local steady-state calculation constrained by measured radical levels significantly underestimate $\mathrm{H}_{2} \mathrm{O}_{2}$ mixing ratios in particular in the AMA. The general tendency is that the steady-state model produces the lowest values, with EMAC falling in between steady state and observations (e.g., Fig. 16). A comparison of the 

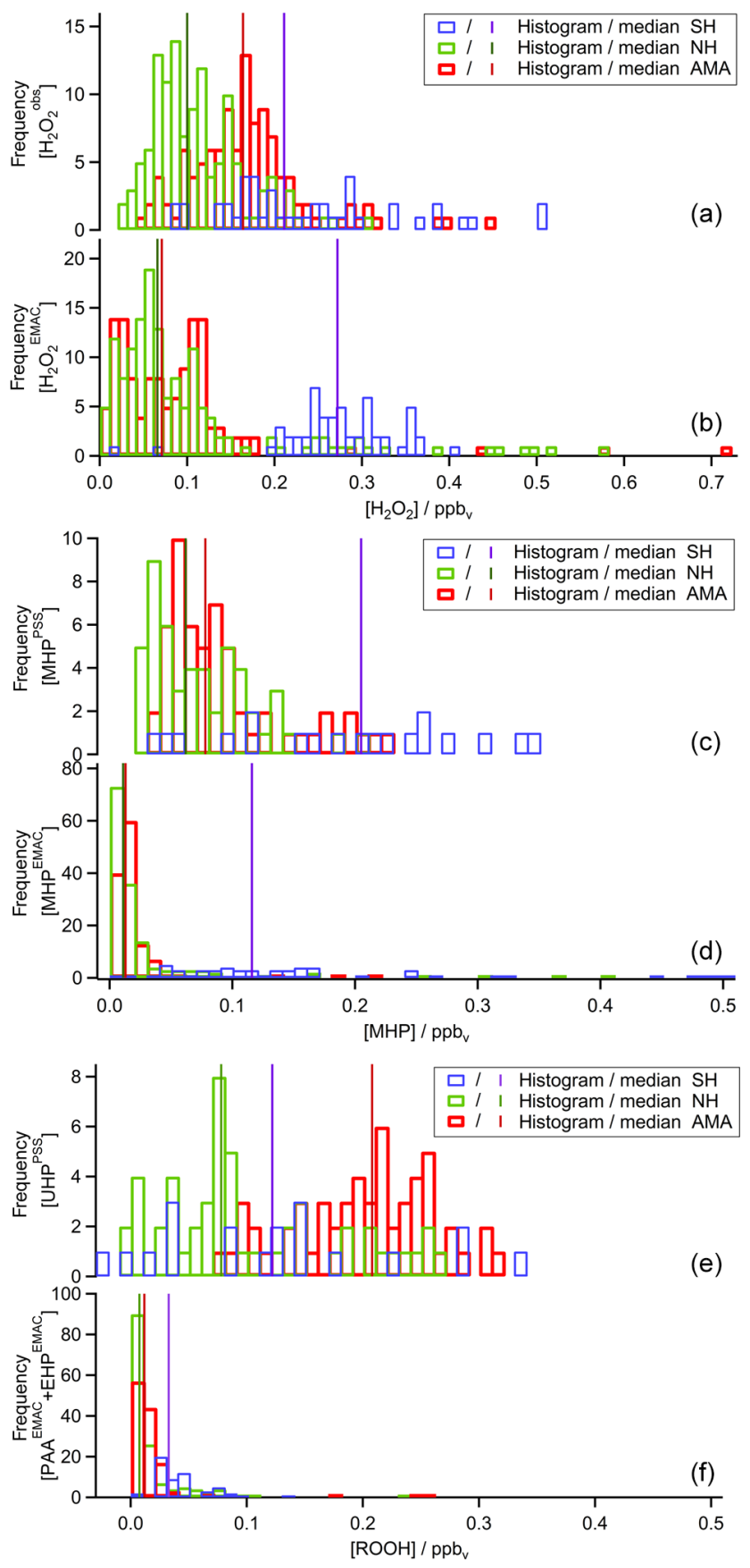

Figure 14. Histograms of $\mathrm{H}_{2} \mathrm{O}_{2}$ obs and $\mathrm{H}_{2} \mathrm{O}_{2}$ EMAC (a, b), $\mathrm{MHP}^{\mathrm{PSS}}$ and MHP${ }^{\mathrm{EMAC}}$ (c, d), and $\mathrm{UHP}^{\mathrm{PSS}}$ and UHP ${ }^{\mathrm{EMAC}}$ (given as PAA ${ }^{\mathrm{EMAC}}$ and $\mathrm{EHP} \mathrm{EMAC}^{\mathrm{e}} \mathbf{e}, \mathbf{f}$ ) mixing ratios during the OMO campaign for NH background (green), $\mathrm{SH}$ (blue), and AMA (red) air masses.

EMAC simulations for the two radicals that affect $\mathrm{H}_{2} \mathrm{O}_{2}$ most strongly $\left(\mathrm{OH}\right.$ and $\mathrm{HO}_{2}$ ) yields a rather good agreement. A scatterplot between modeled and observed $\mathrm{HO}_{2}$ yields a slope of $0.72 \pm 0.01\left(\mathrm{ppt}_{\mathrm{v}} \mathrm{ppt}_{\mathrm{v}}{ }^{-1}\right)$ and an offset of $4.30 \pm 0.09 \mathrm{ppt}_{\mathrm{v}}$, with a regression coefficient $R^{2}$ of 0.58
(Fig. 18 left). The $\mathrm{OH}$ data show more scatter, with a tendency for EMAC to overestimate the mixing ratios (slope: $1.7 \pm 0.2\left(\mathrm{ppt}_{\mathrm{v}} \mathrm{ppt}_{\mathrm{v}}{ }^{-1}\right)$; offset: $-0.1 \pm 0.1 \mathrm{ppt}_{\mathrm{v}}$; regression coefficient $R^{2}$ : 0.09; Fig. 18 right). Although there is rather good agreement between EMAC simulations and observations for all the species that affect the local photochemical budget of $\mathrm{H}_{2} \mathrm{O}_{2}$, EMAC significantly exceeds PSS calculation for $\mathrm{H}_{2} \mathrm{O}_{2}$. This is an indication that an additional $\mathrm{H}_{2} \mathrm{O}_{2}$ source is accounted for in the global model and that the local photostationary-state assumption is not fulfilled. The additional source is attributed to transport associated with deep convection over India, yielding an upwind source of $\mathrm{H}_{2} \mathrm{O}_{2}$ that is significant throughout the western part of the AMA. In the AMA, clouds are absent so that gas-phase photochemical processes may determine the lifetime of $\mathrm{H}_{2} \mathrm{O}_{2}$. Based on observed $\mathrm{OH}^{\text {obs }}$ levels and photolysis frequencies during $\mathrm{OMO}$, the $\mathrm{H}_{2} \mathrm{O}_{2}$ lifetime in the upper troposphere is of the order of several days, sufficiently long for the excess $\mathrm{H}_{2} \mathrm{O}_{2}$ to reach the western parts of the AMA, producing the observed longitudinal $\mathrm{H}_{2} \mathrm{O}_{2}$ gradient observed in both observations and EMAC simulations (Fig. 16). The total amount of $\mathrm{H}_{2} \mathrm{O}_{2}$ injected into the UT by convective outflow depends on the scavenging efficiency (Mari et al., 2000; Barth et al., 2016; Bozem et al., 2017). Differences between $\mathrm{H}_{2} \mathrm{O}_{2}{ }^{\text {obs }}$ and $\mathrm{H}_{2} \mathrm{O}_{2}{ }^{\text {EMAC }}$ are most likely due to an overestimation of scavenging in the model as also pointed out by Klippel et al., 2011).

To investigate this assumption we performed a sensitivity study with the wet scavenging for all soluble species being switched off globally. The result is shown in Fig. 19. The $\mathrm{H}_{2} \mathrm{O}_{2}$ EMAC mixing ratios significantly increase with longitude by a factor of 3-4 and thus to the level of $\mathrm{H}_{2} \mathrm{O}_{2}{ }^{\text {obs }}$. Please note that significant enhancements in MHP ${ }^{\mathrm{EMAC}}$ and $\mathrm{ROOH}^{\mathrm{EMAC}}$ were not found in the sensitivity study with switched-off scavenging, indicating that the strong underestimation by the model of these species is not due to an overestimation of wet removal in convective clouds. Instead, we found that EMAC underestimates ROOH in all air masses and not only in the AMA. The reasons for this underestimation are unknown. In a previous comparison of MHP observations and EMAC simulations over Europe for July 2007, Klippel et al. (2011) also reported a difference of a factor of 10 in the upper troposphere, while a comparison during the fall season (October 2006) yielded a rather good agreement (within a factor of 2).

There is a rather large uncertainty regarding the scavenging efficiency of MHP in deep convection (Barth et al., 2016). For the Trace A campaign Mari et al. (2000) found observed (modeled) enhancement ratios of postconvective mixing ratios in comparison to preconvective mixing ratios of 11 (9.5) for MHP and 1.9 (1.2) for $\mathrm{H}_{2} \mathrm{O}_{2}$. Such efficient transport in the Indian summer monsoon would yield a strong source of upper-tropospheric MHP, explaining the large enhancement of $\mathrm{ROOH}^{\mathrm{obs}}$ in the AMA described here. Please note that large enhancements of MHPEMAC and $\mathrm{ROOH}^{\mathrm{EMAC}}$ were not 


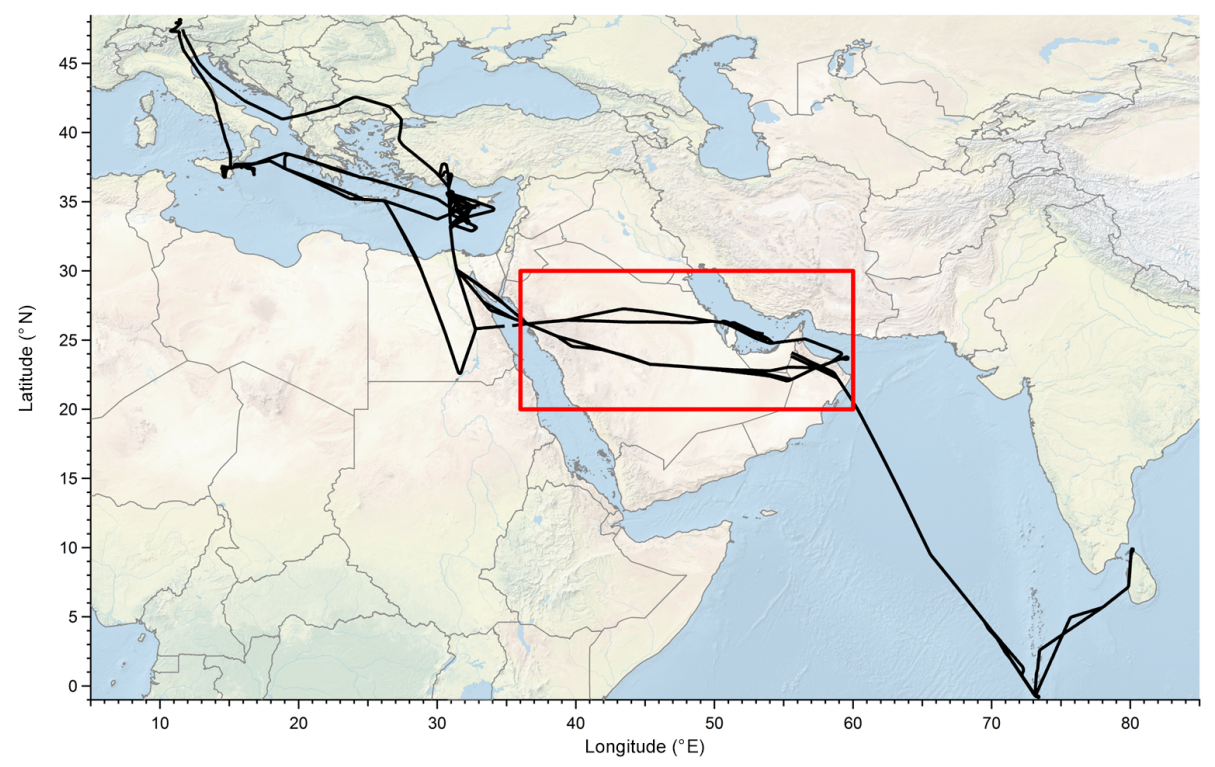

Figure 15. Location of measurements used for the longitudinal gradient study (red box) out of all flight tracks (black).

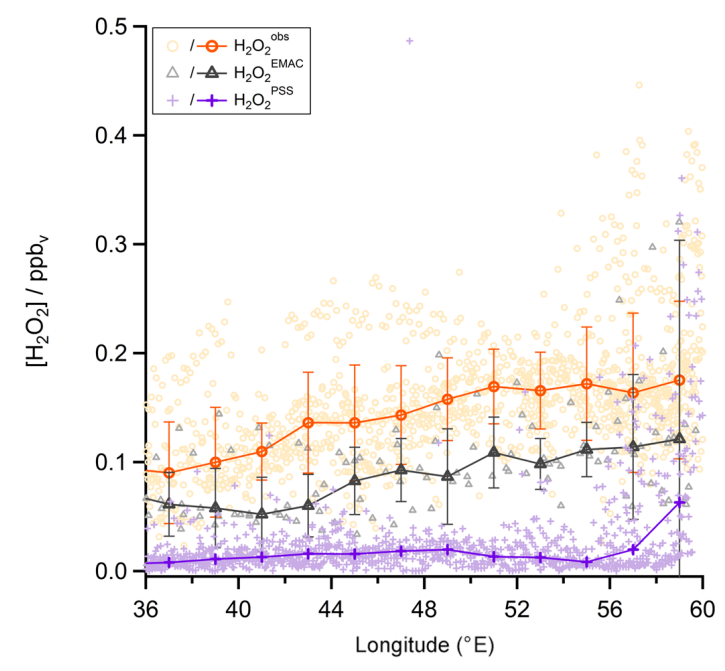

Figure 16. Longitudinal trends of $\mathrm{H}_{2} \mathrm{O}_{2}$ obs mixing ratios (orange circles), $\mathrm{H}_{2} \mathrm{O}_{2}$ EMAC (black triangles), and $\mathrm{H}_{2} \mathrm{O}_{2}$ PSS (purple plus signs). The data are shown in the light colors while the darker ones represent the medians.

found in the sensitivity study with switched-off scavenging, indicating that the strong underestimation by the model of those species is not due to an overestimation of wet removal in convective clouds. It seems that a large part of the UHP ${ }^{\mathrm{PSS}}$ is actually MHP advected throughout the AMA after deep convective transport over India. In the EMAC simulations the transport of MHP is less efficient, and thus MHPEMAC is lower than MHP ${ }^{\mathrm{PSS}}$ and $\mathrm{UHP}^{\mathrm{PSS}}$. Please note that EMAC has a general tendency to overestimate $\mathrm{CO}$ in the UT, especially for the $\mathrm{NH}$ background, while it tends to underestimate $\mathrm{CH}_{4}$ (Tomsche et al., 2019). The deviations in general are not

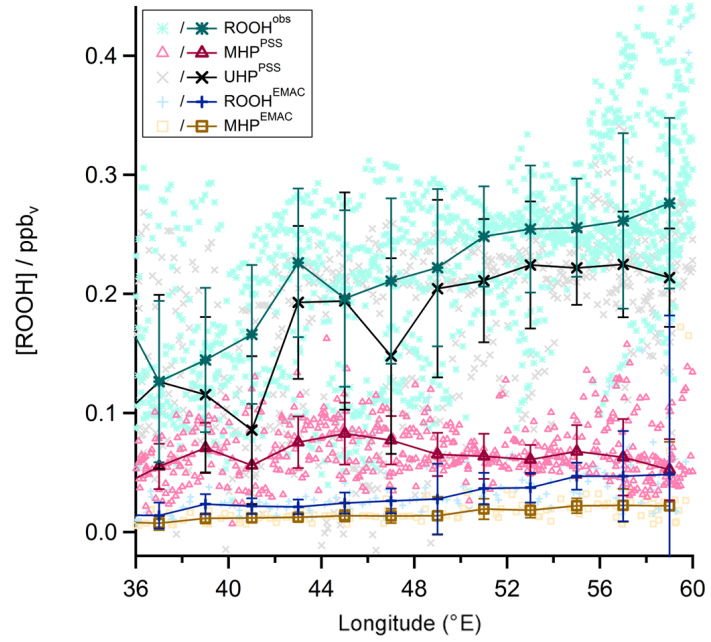

Figure 17. Longitudinal trends of $\mathrm{ROOH}^{\mathrm{obs}}$ mixing ratios (green asterisks), ROOH ${ }^{\mathrm{EMAC}}$ (blue plus signs), and mixing ratios for $\mathrm{MHP}^{\mathrm{PSS}}$ (pink triangles) and UHP ${ }^{\mathrm{PSS}}$ (black crosses) as well as MHPEMAC (yellow squares). The data are shown in the light colors, while the darker ones represent the medians.

significant, with the exception of $\mathrm{CH}_{4}$ in the AMA (Table 1 in Tomsche et al., 2019). As discussed in Tomsche et al. (2019), the $\mathrm{CH}_{4}$ mixing ratio in the AMA depends of the colocation of convection and underlying methane sources. The model resolution of $2.8^{\circ} \times 2.8^{\circ}$ is not sufficient to resolve smallscale variations in both convection and $\mathrm{CH}_{4}$ source distribution. The $\mathrm{H}_{2} \mathrm{O}_{2}$ mixing ratio over the Indian subcontinent is not expected to show large spatial variations since latitudinal gradients are generally small (see, e.g., Klippel et al., 2011). Therefore, we do not expect that the model resolution will 

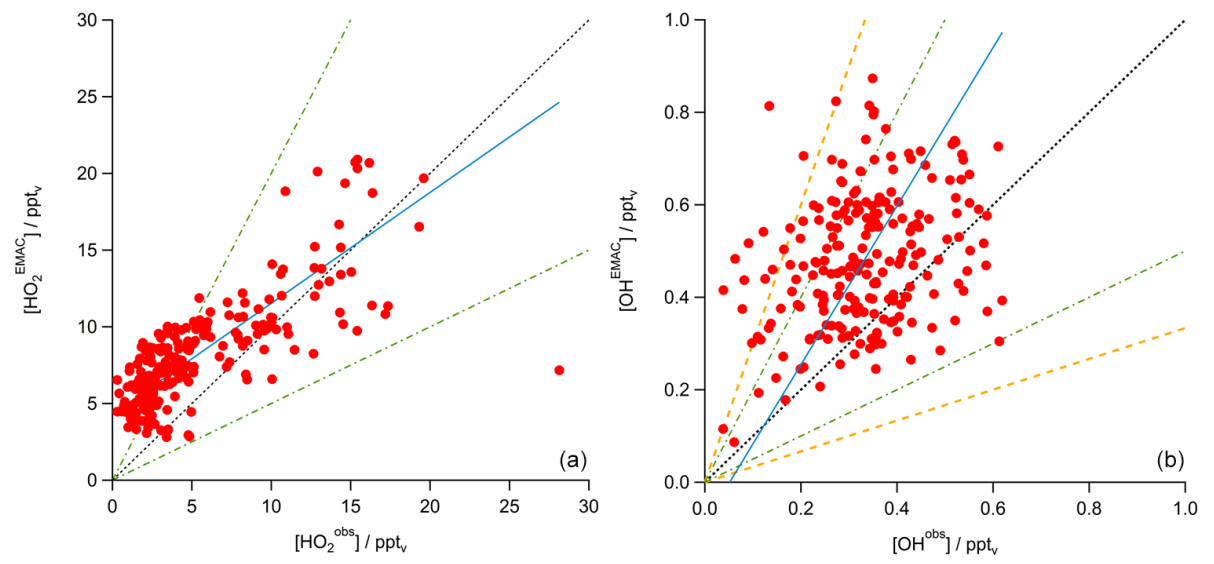

Figure 18. Scatterplot of $\mathrm{HO}_{2}{ }^{\text {obs }}$ and $\mathrm{HO}_{2}{ }^{\text {EMAC }}$ data (a) and $\mathrm{OH}^{\text {obs }}$ and $\mathrm{OH}^{\text {EMAC }}$ data (b; both red) with the $1: 1$ (black), $1: 2$, and $2: 1$ (both green) lines. The blue line shows the calculated least-orthogonal-distance fit.

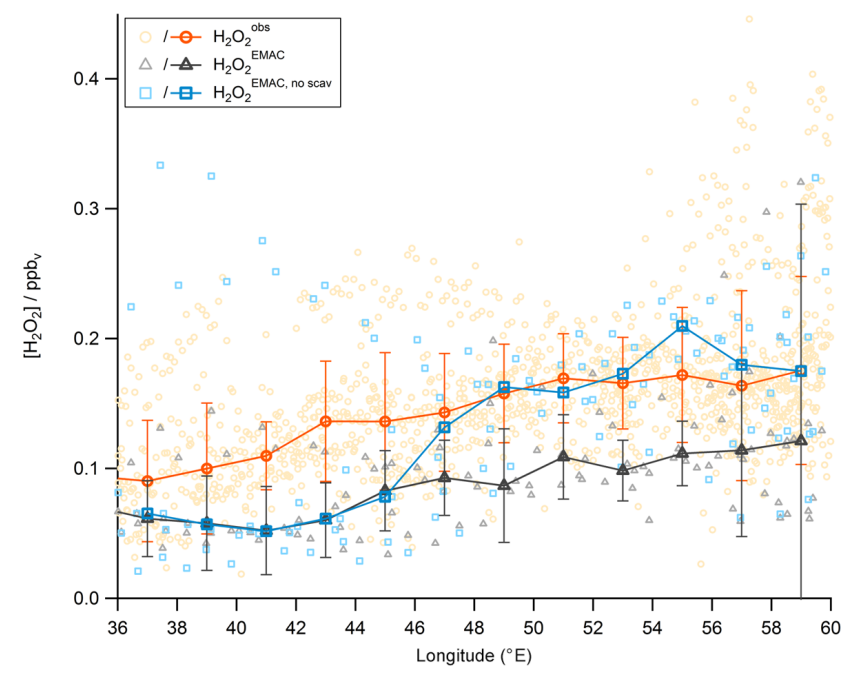

Figure 19. Longitudinal trends of $\mathrm{H}_{2} \mathrm{O}_{2}$ obs mixing ratios (orange circles), $\mathrm{H}_{2} \mathrm{O}_{2}$ EMAC (black triangles), and the sensitivity study without scavenging in $\mathrm{H}_{2} \mathrm{O}_{2}$ EMAC (blue circles). The data are shown in the light colors, while the darker ones represent the medians.

have a strong influence on the deviation between $\mathrm{H}_{2} \mathrm{O}_{2}{ }^{\text {obs }}$ and $\mathrm{H}_{2} \mathrm{O}_{2}{ }^{\mathrm{EMAC}}$. Another uncertainty arises from missing information on the absolute mixing ratios of $\mathrm{H}_{2} \mathrm{O}_{2}$, MHP, and higher organic hydroperoxides in the inflow region of deep convection over India since observations of these species in the boundary layer over India are not available. Note that the amount of hydrogen peroxide and number of organic hydroperoxides transported to the upper troposphere depends on the scavenging efficiency and on the mixing ratios of the individual species in the inflow region (Barth et al., 2016; Bozem et al., 2017). Thus, an underestimation of hydroperoxides in the upper troposphere after convective injection can be due either to an underestimation of the scavenging efficiency for individual species, an underestimation of their mixing ratio in the inflow region, or a combination of both and might differ for individual hydroperoxides. Due to a lack of observations in the inflow and outflow region of convection over India, this question cannot be resolved in this study.

\section{Conclusions}

Hydrogen peroxide and organic hydroperoxides were measured during the OMO campaign in the upper troposphere in NH background air over the western Mediterranean, the Asian summer monsoon anticyclone over the Arabian Peninsula, and the SH over the Maldives and the Indian Ocean in summer 2015. The observed mixing ratios for background conditions in the $\mathrm{NH}$ and $\mathrm{SH}$ are in line with previous studies described in the literature. A case study (of Flight 17) revealed enhanced $\mathrm{H}_{2} \mathrm{O}_{2}{ }^{\text {obs }}$ and $\mathrm{ROOH}^{\mathrm{obs}}$ mixing ratios in the AMA relative to the NH background. Similar results are found for other flights throughout the campaign. The atmospheric chemistry general circulation model EMAC slightly underestimates $\mathrm{H}_{2} \mathrm{O}_{2}{ }^{\text {EMAC }}$ in the $\mathrm{NH}$ background (medians: $66 \mathrm{ppt}_{\mathrm{v}}$ vs. $100 \mathrm{ppt}_{\mathrm{v}}$ ), significantly underestimates it in the AMA (medians: $71 \mathrm{ppt}_{\mathrm{v}}$ vs. $164 \mathrm{ppt}_{\mathrm{v}}$ ), and overestimates it in the SH (medians: 272 ppt $_{\mathrm{v}}$ vs. $211 \mathrm{ppt}_{\mathrm{v}}$ ). Steady-state calculations for $\mathrm{H}_{2} \mathrm{O}_{2}{ }^{\mathrm{PSS}}$ and $\mathrm{MHP}{ }^{\mathrm{PSS}}$ based on observed precursors yield much lower values compared to $\mathrm{H}_{2} \mathrm{O}_{2}{ }^{\text {obs }}$ and MHP ${ }^{\text {PSS }}$ by roughly a factor of 3 , in particular in the AMA, resulting in a large contribution of an unidentified organic hydroperoxide (UHP ${ }^{\mathrm{PSS}}$ ) in air masses affected by the AMA. A comparison between EMAC simulations and $\mathrm{HO}_{x}$ levels shows a good agreement, indicating that deviations between $\mathrm{H}_{2} \mathrm{O}_{2}{ }^{\text {EMAC }}$ and $\mathrm{H}_{2} \mathrm{O}_{2}{ }^{\mathrm{PSS}}$ levels are due to transport. Convective injection of $\mathrm{H}_{2} \mathrm{O}_{2}$ (and $\mathrm{ROOH}$ ) into the upper troposphere over India most likely forms a pool of hydroperoxides in the upper troposphere that subsequently influences the western AMA, giving rise to a significant longitudinal gradient of $\mathrm{H}_{2} \mathrm{O}_{2}$ and $\mathrm{ROOH}$ mixing ratios, with increasing 
values towards the center of the AMA. It is likely that next to an unidentified organic hydroperoxide (e.g., PAA), at least part of $\mathrm{UHP}^{\mathrm{PSS}}$ is due to additional MHP from an upwind source. A sensitivity study using EMAC with no scavenging tends to reproduce the observed longitudinal gradients in $\mathrm{H}_{2} \mathrm{O}_{2}$, although it does not increase the level of ROOH. The reasons for this different behavior are unclear.

Data availability. The data are available from the HALO database (https://halo-db.pa.op.dlr.de/mission/0, OMO, 2015).

Author contributions. $\mathrm{BH}$ and $\mathrm{SH}$ were responsible for $\mathrm{H}_{2} \mathrm{O}_{2}$ and $\mathrm{ROOH}$ measurements and data. $\mathrm{BH}$ conducted further data analysis and wrote the original draft of the paper in close cooperation with $\mathrm{HF}$. $\mathrm{CH}_{4}$ and $\mathrm{CO}$ data were provided by $\mathrm{LT} ; \mathrm{HO}_{x}$ data by DM, $\mathrm{MM}$, and $\mathrm{HH} ; \mathrm{O}_{3}$ and acetone data by $\mathrm{MN}$ and $\mathrm{AZ}$; photolysis frequencies by $\mathrm{BB}$ and $\mathrm{NO}$; and $\mathrm{NO}_{y}$ data by $\mathrm{HZ}$ and GS. AP was responsible for the EMAC model simulations. JL was the principal investigator of the OMO mission. All authors were involved in the review and editing of the paper.

Competing interests. The authors declare that they have no conflict of interest.

Acknowledgements. We would like to thank all of the participants of the OMO mission, the German Aerospace Center (DLR), and EDT Offshore Ltd in Cyprus for their cooperation during the mission. We further thank Rainer Königstedt for installing the TRIHOP instrument and Uwe Parchatka for supporting the measurements of $\mathrm{CO}$ and $\mathrm{CH}_{4}$.

Financial support. The article processing charges for this openaccess publication were covered by the Max Planck Society.

Review statement. This paper was edited by Barbara Ervens and reviewed by two anonymous referees.

\section{References}

AEROLASER: AL2021 $\mathrm{H}_{2} \mathrm{O}_{2}$-Monitor User Manual, Version 2.20, Rev.02, Garmisch-Partenkirchen, Germany, 2006.

Atkinson, R., Baulch, D. L., Cox, R. A., Crowley, J. N., Hampson, R. F., Hynes, R. G., Jenkin, M. E., Rossi, M. J., and Troe, J.: Evaluated kinetic and photochemical data for atmospheric chemistry: Volume I - gas phase reactions of $\mathrm{O}_{x}, \mathrm{HO}_{x}$, $\mathrm{NO}_{x}$ and $\mathrm{SO}_{x}$ species, Atmos. Chem. Phys., 4, 1461-1738, https://doi.org/10.5194/acp-4-1461-2004, 2004.

Atkinson, R., Baulch, D. L., Cox, R. A., Crowley, J. N., Hampson, R. F., Hynes, R. G., Jenkin, M. E., Rossi, M. J., Troe, J., and IUPAC Subcommittee: Evaluated kinetic and photochemi- cal data for atmospheric chemistry: Volume II - gas phase reactions of organic species, Atmos. Chem. Phys., 6, 3625-4055, https://doi.org/10.5194/acp-6-3625-2006, 2006.

Barret, B., Sauvage, B., Bennouna, Y., and Le Flochmoen, E.: Upper-tropospheric $\mathrm{CO}$ and $\mathrm{O}_{3}$ budget during the Asian summer monsoon, Atmos. Chem. Phys., 16, 9129-9147, https://doi.org/10.5194/acp-16-9129-2016, 2016.

Barth, M. C., Bela, M. M., Fried, A., Wennberg, P. O., Crounse, J. D., St. Clair, J. M., Blake, N. J., Blake, D. R., Homeyer, C. R., Brune, W. H., Zhang, L., Mao, J., Ren, X., Ryerson, T. B., Pollack, I. B., Peischl, J., Cohen, R. C., Nault, B. A., Huey, L. G., Liu, X., and Cantrell, C. A.: Convective transport and scavenging of peroxides by thunderstorms observed over the central U.S. during DC3, J. Geophys. Res.-Atmos., 121, 4272-4295, https://doi.org/10.1002/2015JD024570, 2016.

Bohn, B. and Lohse, I.: Calibration and evaluation of CCD spectroradiometers for ground-based and airborne measurements of spectral actinic flux densities, Atmos. Meas. Tech., 10, 31513174, https://doi.org/10.5194/amt-10-3151-2017, 2017.

Bozem, H., Pozzer, A., Harder, H., Martinez, M., Williams, J., Lelieveld, J., and Fischer, H.: The influence of deep convection on $\mathrm{HCHO}$ and $\mathrm{H}_{2} \mathrm{O}_{2}$ in the upper troposphere over Europe, Atmos. Chem. Phys., 17, 11835-11848, https://doi.org/10.5194/acp-17-11835-2017, 2017.

Burkholder, J. B., Sander, S. P., Abbatt, J., Barker, J. R., Huie, R. E., Kolb, C. E., Kurylo, M. J., Orkin, V. L., Wilmouth, D. M., and Wine, P. H.: Chemical Kinetics and Photochemical Data for Use in Atmospheric Studies, JPL Publication 15-10, Jet Propulsion Laboratory, Pasadena, 2015.

Calvert, J. G., Lazrus, A., Kok, G. L., Heikes, B. G., Walega, J. G., Lind, J., and Cantrell, C. A.: Chemical mechanisms of acid generation in the troposphere, Nature, 317, 27-35, https://doi.org/10.1038/317027a0, 1985.

Crutzen, P. J., Lawrence, M. G., and Pöschl, U.: On the background photochemistry of tropospheric ozone, Tellus B, 51, 123-146, https://doi.org/10.3402/tellusb.v51i1.16264, 1999.

Daum, P. H., Kleinman, L. I., Hills, A. J., Lazrus, A. L., Leslie, A. C. D., Busness, K., and Boatman, J.: Measurement and interpretation of concentrations of $\mathrm{H}_{2} \mathrm{O}_{2}$ and related species in the upper midwest during summer, J. Geophys. Res., 95, 9857-9871, https://doi.org/10.1029/JD095iD07p09857, 1990.

Emanuel, K. A. and Zivkovic-Rothman, M.: Development and Evaluation of a Convection Scheme for Use in Climate Models, J. Atmos. Sci., 1766-1782, https://doi.org/10.1175/15200469(1999)056<1766:DAEOAC>2.0.CO;2, 1999.

Faloona, I., Tan, D., Brune, W. H., Jaeglé, L., Jacob, D. J., Kondo, Y., Koike, M., Chatfield, R., Pueschel, R., Ferry, G., Sachse, G., Vay, S., Anderson, B., Hannon, J., and Fuelberg, H.: Observations of $\mathrm{HO}_{x}$ and its relationship with $\mathrm{NO}_{x}$ in the upper troposphere during SONEX, J. Geophys. Res., 105, 3771-3783, https://doi.org/10.1029/1999JD900914, 2000.

Faloona, I. C., Tan, D., Lesher, R. L., Hazen, N. L., Frame, C. L., Simpas, J. B., Harder, H., Martinez, M., Di Carlo, P., Ren, X., and Brune, W. H.: A Laser-induced Fluorescence Instrument for Detecting Tropospheric $\mathrm{OH}$ and $\mathrm{HO}_{2}$ : Characteristics and Calibration, J. Atmos. Chem., 47, 139-167, https://doi.org/10.1023/B:JOCH.0000021036.53185.0e, 2004.

Gettelman, A., Kinnison, D. E., Dunkerton, T. J., and Brasseur, G. P.: Impact of monsoon circulations on the upper tropo- 
sphere and lower stratosphere, J. Geophys. Res., 109, D22101, https://doi.org/10.1029/2004JD004878, 2004.

Heikes, B. G.: Formaldehyde and hydroperoxides at Mauna Loa Observatory, J. Geophys. Res., 97, 18001, https://doi.org/10.1029/92JD00268, 1992.

Heikes, B. G., Lee, M., Bradshaw, J., Sandholm, S., Davis, D. D., Crawford, J., Rodriguez, J., Liu, S., McKeen, S., Thornton, D., Bandy, A., Gregory, G., Talbot, R., and Blake, D.: Hydrogen peroxide and methylhydroperoxide distributions related to ozone and odd hydrogen over the North Pacific in the fall of 1991, J. Geophys. Res., 101, 1891-1905, https://doi.org/10.1029/95JD01364, 1996.

Hoffmann, M. R. and Edwards, J. O.: Kinetics of the oxidation of sulfite by hydrogen peroxide in acidic solution, J. Phys. Chem., 79, 2096-2098, https://doi.org/10.1021/j100587a005, 1975.

Jackson, A. V. and Hewitt, C. N.: Hydrogen peroxide and organic hydroperoxide concentrations in air in a eucalyptus forest in central Portugal, Atmos. Environ., 30, 819-830, https://doi.org/10.1016/1352-2310(95)00348-7, 1996.

Jacob, P. and Klockow, D.: Hydrogen peroxide measurements in the marine atmosphere, J. Atmos. Chem., 15, 353-360, https://doi.org/10.1007/BF00115404, 1992.

Jaeglé, L., Jacob, D. J., Wennberg, P. O., Spivakovsky, C. M., Hanisco, T. F., Lanzendorf, E. J., Hintsa, E. J., Fahey, D. W., Keim, E. R., Proffitt, M. H., Atlas, E. L., Flocke, F., Schauffler, S., McElroy, C. T., Midwinter, C., Pfister, L., and Wilson, J. C.: Observed $\mathrm{OH}$ and $\mathrm{HO}_{2}$ in the upper troposphere suggest a major source from convective injection of peroxides, Geophys. Res. Lett., 24, 3181-3184, https://doi.org/10.1029/97GL03004, 1997.

Jaeglé, L., Jacob, D. J., Brune, W. H., Faloona, I., Tan, D., Heikes, B. G., Kondo, Y., Sachse, G. W., Anderson, B., Gregory, G. L., Singh, H. B., Pueschel, R., Ferry, G., Blake, D. R., and Shetter, R. E.: Photochemistry of $\mathrm{HO}_{x}$ in the upper troposphere at northern midlatitudes, J. Geophys. Res., 105, 3877-3892, https://doi.org/10.1029/1999JD901016, 2000.

Jöckel, P., Tost, H., Pozzer, A., Kunze, M., Kirner, O., Brenninkmeijer, C. A. M., Brinkop, S., Cai, D. S., Dyroff, C., Eckstein, J., Frank, F., Garny, H., Gottschaldt, K.-D., Graf, P., Grewe, V., Kerkweg, A., Kern, B., Matthes, S., Mertens, M., Meul, S., Neumaier, M., Nützel, M., Oberländer-Hayn, S., Ruhnke, R., Runde, T., Sander, R., Scharffe, D., and Zahn, A.: Earth System Chemistry integrated Modelling (ESCiMo) with the Modular Earth Submodel System (MESSy) version 2.51, Geosci. Model Dev., 9, 1153-1200, https://doi.org/10.5194/gmd-9-1153-2016, 2016.

Klippel, T., Fischer, H., Bozem, H., Lawrence, M. G., Butler, T., Jöckel, P., Tost, H., Martinez, M., Harder, H., Regelin, E., Sander, R., Schiller, C. L., Stickler, A., and Lelieveld, J.: Distribution of hydrogen peroxide and formaldehyde over Central Europe during the HOOVER project, Atmos. Chem. Phys., 11, 4391-4410, https://doi.org/10.5194/acp-11-4391-2011, 2011.

Lawrence, M. G. and Lelieveld, J.: Atmospheric pollutant outflow from southern Asia: a review, Atmos. Chem. Phys., 10, 1101711096, https://doi.org/10.5194/acp-10-11017-2010, 2010.

Lazrus, A. L., Kok, G. L., Gitlin, S. N., Lind, J. A., and McLaren, S. E.: Automated fluorimetric method for hydrogen peroxide in atmospheric precipitation, Anal. Chem., 57, 917-922, https://doi.org/10.1021/ac00281a031, 1985.

Lazrus, A. L., Kok, G. L., Lind, J. A., Gitlin, S. N., Heikes, B. G., and Shetter, R. E.: Automated fluorometric method for hydrogen peroxide in air, Anal. Chem., 58, 594-597, https://doi.org/10.1021/ac00294a024, 1986.

Lee, M., Heikes, B. G., and O'Sullivan, D. W.: Hydrogen peroxide and organic hydroperoxide in the troposphere: A review, Atmos. Environ., 34, 3475-3494, https://doi.org/10.1016/S13522310(99)00432-X, 2000.

Lelieveld, J. and Crutzen, P. J.: Influences of cloud photochemical processes on tropospheric ozone, Nature, 343, 227-233, https://doi.org/10.1038/343227a0, 1990.

Lelieveld, J., Berresheim, H., Borrmann, S., Crutzen, P. J., Dentener, F. J., Fischer, H., Feichter, J., Flatau, P. J., Heland, J., Holzinger, R., Korrmann, R., Lawrence, M. G., Levin, Z., Markowicz, K. M., Mihalopoulos, N., Minikin, A., Ramanathan, V., Reus, M. de, Roelofs, G. J., Scheeren, H. A., Sciare, J., Schlager, H., Schultz, M., Siegmund, P., Steil, B., Stephanou, E. G., Stier, P., Traub, M., Warneke, C., Williams, J., and Ziereis, H.: Global air pollution crossroads over the Mediterranean, Science, 298, 794-799, https://doi.org/10.1126/science.1075457, 2002.

Lelieveld, J., Bourtsoukidis, E., Brühl, C., Fischer, H., Fuchs, H., Harder, H., Hofzumahaus, A., Holland, F., Marno, D., Neumaier, M., Pozzer, A., Schlager, H., Williams, J., Zahn, A., and Ziereis, H.: The South Asian monsoon-pollution pump and purifier, Science, 361, 270-273, https://doi.org/10.1126/science.aar2501, 2018.

Levy, H.: Normal atmosphere: large radical and formaldehyde concentrations predicted, Science, 173, 141-143, https://doi.org/10.1126/science.173.3992.141, 1971.

Lind, J. A. and Kok, G. L.: Henry's law determinations for aqueous solutions of hydrogen peroxide, methylhydroperoxide, and peroxyacetic acid, J. Geophys. Res., 91, 7889-7895, https://doi.org/10.1029/JD091iD07p07889, 1986.

Lind, J. A. and Kok, G. L.: Correction to "Henry's law determinations for aqueous solutions of hydrogen peroxide, methylhydroperoxide, and peroxyacetic acid”, J. Geophys. Res., 99, 21119, https://doi.org/10.1029/94JD01155, 1994.

Mari, C., Jacob, D. J., and Bechtold, P.: Transport and scavenging of soluble gases in a deep convective cloud, J. Geophys. Res., 105, 22255-22267, https://doi.org/10.1029/2000JD900211, 2000.

Mari, C., Saüt, C., Jacob, D. J., Staudt, A., Avery, M. A., Brune, W. H., Faloona, I., Heikes, B. G., Sachse, G. W., Sandholm, S. T., Singh, H. B., and Tan, D.: On the relative role of convection, chemistry, and transport over the South Pacific Convergence Zone during PEM-Tropics B: A case study, J. Geophys. Res., 108, 401, https://doi.org/10.1029/2001JD001466, 2003.

Martinez, M., Harder, H., Kubistin, D., Rudolf, M., Bozem, H., Eerdekens, G., Fischer, H., Klüpfel, T., Gurk, C., Königstedt, R., Parchatka, U., Schiller, C. L., Stickler, A., Williams, J., and Lelieveld, J.: Hydroxyl radicals in the tropical troposphere over the Suriname rainforest: airborne measurements, Atmos. Chem. Phys., 10, 3759-3773, https://doi.org/10.5194/acp10-3759-2010, 2010.

Nunnermacker, L. J., Weinstein-Lloyd, J. B., Hillery, B., Giebel, B., Kleinman, L. I., Springston, S. R., Daum, P. H., Gaffney, J., Marley, N., and Huey, G.: Aircraft and ground-based measurements of hydroperoxides during the 2006 MILAGRO field campaign, Atmos. Chem. Phys., 8, 7619-7636, https://doi.org/10.5194/acp8-7619-2008, 2008. 
Ojha, N., Pozzer, A., Rauthe-Schöch, A., Baker, A. K., Yoon, J., Brenninkmeijer, C. A. M., and Lelieveld, J.: Ozone and carbon monoxide over India during the summer monsoon: regional emissions and transport, Atmos. Chem. Phys., 16, 3013-3032, https://doi.org/10.5194/acp-16-3013-2016, 2016.

OMO (Oxidation Mechanism Observations): Oxidation Mechanism Observations in the extrattropical free TS, HALO database, available at: https://halo-db.pa.op.dlr.de/mission/0 (last access: 7 November 2019), 2015.

Penkett, S. A., Jones, B., Brich, K. A., and Eggleton, A.: The importance of atmospheric ozone and hydrogen peroxide in oxidising sulphur dioxide in cloud and rainwater, Atmos. Environ., 13, 123-137, https://doi.org/10.1016/0004-6981(79)90251-8, 1979.

Perros, P.: Large-scale distribution of hydrogen peroxide from aircraft measurements during the TROPOZ II experiment, Atmos. Environ. A-Gen., 27, 1695-1708, https://doi.org/10.1016/09601686(93)90232-N, 1993.

Pilz, W. and Johann, I.: Die Bestimmung Kleinster Mengen von Wasserstoffperoxyd in Luft, Int. J Environ. Anal. Chem., 3, $257-$ 270, https://doi.org/10.1080/03067317408071087, 1974.

Prather, M. J. and Jacob, D. J.: A persistent imbalance in $\mathrm{HO}_{x}$ and $\mathrm{NO}_{x}$ photochemistry of the upper troposphere driven by deep tropical convection, Geophys. Res. Lett., 24, 3189-3192, https://doi.org/10.1029/97GL03027, 1997.

Randel, W. J., Park, M., Emmons, L., Kinnison, D., Bernath, P., Walker, K. A., Boone, C., and Pumphrey, H.: Asian monsoon transport of pollution to the stratosphere, Science, 328, 611-613, https://doi.org/10.1126/science.1182274, 2010.

Rauthe-Schöch, A., Baker, A. K., Schuck, T. J., Brenninkmeijer, C. A. M., Zahn, A., Hermann, M., Stratmann, G., Ziereis, H., van Velthoven, P. F. J., and Lelieveld, J.: Trapping, chemistry, and export of trace gases in the South Asian summer monsoon observed during CARIBIC flights in 2008, Atmos. Chem. Phys., 16, 36093629, https://doi.org/10.5194/acp-16-3609-2016, 2016.

Robbin Martin, L. and Damschen, D. E.: Aqueous oxidation of sulfur dioxide by hydrogen peroxide at low pH, Atmos. Environ., 15, 1615-1621, https://doi.org/10.1016/0004-6981(81)90146-3, 1981.

Roeckner, E., Brokopf, R., Esch, M., Giorgetta, M., Hagemann, S., Kornblueh, L., Manzini, E., Schlese, U., and Schulzweida, U.: Sensitivity of Simulated Climate to Horizontal and Vertical Resolution in the ECHAM5 Atmosphere Model, J. Climate, 19, 3771-3791, https://doi.org/10.1175/JCLI3824.1, 2006.

Schiller, C. L., Bozem, H., Gurk, C., Parchatka, U., Königstedt, R., Harris, G. W., Lelieveld, J., and Fischer, H.: Applications of quantum cascade lasers for sensitive trace gas measurements of $\mathrm{CO}, \mathrm{CH}_{4}, \mathrm{~N}_{2} \mathrm{O}$ and HCHO, Appl. Phys. B, 92, 419-430, https://doi.org/10.1007/s00340-008-3125-0, 2008.
Slemr, F. and Tremmel, H. G.: Hydroperoxides in the marine troposphere over the Atlantic Ocean, J. Atmos. Chem., 19, 371-404, https://doi.org/10.1007/BF00694493, 1994.

Snow, J. A.: Winter-spring evolution and variability of $\mathrm{HO}_{x}$ reservoir species, hydrogen peroxide, and methyl hydroperoxide, in the northern middle to high latitudes, J. Geophys. Res., 108, 1890, https://doi.org/10.1029/2002JD002172, 2003.

Snow, J. A., Heikes, B. G., Shen, H., O’Sullivan, D. W., Fried, A., and Walega, J.: Hydrogen peroxide, methyl hydroperoxide, and formaldehyde over North America and the North Atlantic, J. Geophys. Res., 112, 8353, https://doi.org/10.1029/2006JD007746, 2007.

Stohl, A., Forster, C., Frank, A., Seibert, P., and Wotawa, G.: Technical note: The Lagrangian particle dispersion model FLEXPART version 6.2, Atmos. Chem. Phys., 5, 2461-2474, https://doi.org/10.5194/acp-5-2461-2005, 2005.

Stratmann, G., Ziereis, H., Stock, P., Brenninkmeijer, C., Zahn, A., Rauthe-Schöch, A., Velthoven, P. V., Schlager, H., and Volz-Thomas, A.: $\mathrm{NO}$ and $\mathrm{NO}_{y}$ in the upper troposphere: Nine years of CARIBIC measurements onboard a passenger aircraft, Atmos. Environ., 133, 93-111, https://doi.org/10.1016/j.atmosenv.2016.02.035, 2016.

Tadic, I., Parchatka, U., Königstedt, R., and Fischer, H.: In-flight stability of quantum cascade laser-based infrared absorption spectroscopy measurements of atmospheric carbon monoxide, Appl. Phys. B, 123, 805, https://doi.org/10.1007/s00340-0176721-z, 2017.

Tomsche, L., Pozzer, A., Ojha, N., Parchatka, U., Lelieveld, J., and Fischer, H.: Upper tropospheric $\mathrm{CH}_{4}$ and $\mathrm{CO}$ affected by the South Asian summer monsoon during the Oxidation Mechanism Observations mission, Atmos. Chem. Phys., 19, 19151939, https://doi.org/10.5194/acp-19-1915-2019, 2019.

Weinstein-Lloyd, J. B., Lee, J. H., Daum, P. H., Kleinman, L. I., Nunnermacker, L. J., Springston, S. R., and Newman, L.: Measurements of peroxides and related species during the 1995 summer intensive of the Southern Oxidants Study in Nashville, Tennessee, J. Geophys. Res., 103, 22361-22373, https://doi.org/10.1029/98JD01636, 1998.

Zahn, A., Weppner, J., Widmann, H., Schlote-Holubek, K., Burger, B., Kühner, T., and Franke, H.: A fast and precise chemiluminescence ozone detector for eddy flux and airborne application, Atmos. Meas. Tech., 5, 363-375, https://doi.org/10.5194/amt-5363-2012, 2012.

Ziereis, H., Schlager, H., Schulte, P., van Velthoven, P. F. J., and Slemr, F.: Distributions of $\mathrm{NO}, \mathrm{NO}_{x}$ and $\mathrm{NO}_{y}$ in the upper troposphere and lower stratosphere between $28^{\circ}$ and $61^{\circ} \mathrm{N}$ during POLINAT 2, J. Geophys. Res., 105, 3653-3664, https://doi.org/10.1029/1999JD900870, 2000. 